\title{
Attentional resources in timing: Interference effects in concurrent temporal and nontemporal working memory tasks
}

\author{
SCOTT W. BROWN \\ University of Southern Maine, Portland, Maine
}

\begin{abstract}
Three experiments examined interference effects in concurrent temporal and nontemporal tasks. The timing task in each experiment required subjects to generate a series of 2-or 5-sec temporal productions. The nontemporal tasks were pursuit rotor tracking (Experiment 1), visual search (Experiment 2), and mental arithmetic (Experiment 3). Each nontemporal task had two levels of difficulty. All tasks were performed under both single- and dual-task conditions. A simple attentional allocation model predicts bidirectional interference between concurrent tasks. The main results showed the classic interference effect in timing. That is, the concurrent nontemporal tasks caused temporal productions to become longer (longer productions represent a shortening of perceived time) and/or more variable than did timing-only conditions. In general, the difficult version of each nontemporal task disrupted timing more than the easier version. The timing data also exhibited a serial lengthening effect, in which temporal productions became longer across trials. Nontemporal task performance showed a mixed pattern. Tracking and visual search were essentially unaffected by the addition of a timing task, whereas mental arithmetic was disrupted by concurrent timing. These results call for a modification of the attentional allocation model to incorporate the idea of specialized processing resources. Two major theoretical frameworks-multiple resource theory and the working memory model-are critically evaluated with respect to the resource demands of timing and temporal/nontemporal dual-task performance.
\end{abstract}

The interference effect is one of the most consistent findings in the time perception literature. The effect refers to a disruption in timing that occurs when subjects are required to perform some demanding nontemporal task during the interval. The usual result is that perceived time becomes shortened. Because of differences between time judgment methods (see below), this effect is manifested as either shorter verbal estimations and reproductions or longer temporal productions. Time judgments also may display more error and variability under nontemporal task conditions than under control (no-task) conditions. This paper explores the nature of this effect, with special reference to the role of attentional processes in timing. First, a review of the empirical and theoretical work in the area is presented, and issues involving mutual interference between temporal and nontemporal processing are raised. Three experiments designed to address these issues are reported. The paper concludes with a discussion centering on the relationship between timing and current models of attentional resources.

Some of this work was presented at the Fourth International Workshop on Rhythm Perception and Production, Bourges, France, June 1992. Special thanks are extended to Peter N. Johansson, who recruited subjects and collected data. The author also thanks Mike Braunstein, Francoise Macar, and two anonymous reviewers for their helpful comments on an earlier version of this paper. Correspondence should be addressed to S. W. Brown, Department of Psychology, University of Southern Maine, Portland, ME 04104-9300(e-mail: swbrown@usm. maine.edu).

\section{ATTENTION IN TIMING}

All studies discussed in this paper have been conducted under the prospective paradigm, in which subjects are informed at the start of the experiment that the task is to judge time. These instructions are designed to focus awareness on the passage of time itself. Although Block (1990) has objected to the term attention to time as being too vague, other writers have characterized this condition as "the experience of time-in-passing" (Hicks, Miller, Gaes, \& Bierman, 1977), a "perceptual readiness" to process temporal cues (Zakay, 1992), or a state of "heightened temporal awareness" related to boredom, impatience, and anticipation (Brown, 1985). Attention to time sometimes includes various self-generated timekeeping strategies (Poynter, 1989), including subvocal counting, repeating rhythmical motor sequences, and visualizing clock faces. Michon (1972, 1985; Michon \& Jackson, 1984) contends that temporal and nontemporal information processing are functionally equivalent and that attention to time is similar in principle to attention to any other perceptual or cognitive events. Thus, a concurrent nontemporal task competes with timekeeping by distracting attention away from time.

\section{Interference Studies}

Many different types of tasks have been used as distractor or interference tasks in timing studies. These tasks tap into a wide range of processes, including motor 
skills, perceptual discrimination, visual and verbal processing, memory search, and response decisions. There is a growing literature on this topic, and many papers include multiple experiments. Over 80 individual experiments published between 1924 and 1995 are reviewed here; all examined the effects of task demands on time judgment performance. Only 9 studies $(11 \%)$ were found that either failed to produce the interference effect or produced an opposite pattern. Although this listing is not exhaustive, it probably captures most of the main studies in the area.

Numerous perceptual tasks have been shown to disrupt timing. Task conditions requiring perceptual-motor coordination, such as mirror drawing (Brown, 1985, Experiment 1; Wilsoncroft \& Stone, 1975), reversed printing (DeWolfe \& Duncan, 1959), and mechanical problem solving (Hawkins \& Meyer, 1965), shorten perceived time relative to control (no-task) conditions. Similarly, perceptual judgment tasks involving weight discrimination (Harton, 1938b), loudness discrimination (Grondin \& Macar, 1992; Macar, Grondin, \& Casini, 1994, Experiment 3), brightness discrimination (Casini, Macar, \& Grondin, 1992, Experiment 2; Macar et al., 1994, Experiment 2), and tactile judgment (Zakay, 1993a, Experiment 2) all disrupt timing, although there are exceptions (Thomas \& Cantor, 1975; Zakay, 1993a, Experiment 1).

Some studies have paired timing with tasks emphasizing visual or spatial processing, such as maze learning (Cohen, 1971; Harton, 1942), mental rotation (Fortin \& Breton, 1995, Experiment 3), mirror reading (Gulliksen, 1927), and form completion (Zakay, 1993b). In all these studies, the concurrent task shortened perceived time. Visual search tasks, in which subjects must scan an array of distractor stimuli for the presence (or absence) of a target stimulus, cause either a shortening of perceived time (Fortin, Rousseau, Bourque, \& Kirouac, 1993, Experiment 2) or more error in time judgments (Thomas \& Cantor, 1978) relative to control conditions involving timing only. However, Fortin et al. (1993, Experiments 3 and 4) reported that increased task difficulty (as defined by increased numbers of distractors) did not lead to a further shortening of perceived time.

Studies employing verbal tasks have produced a generally consistent pattern of results. Several studies have shown that the Stroop task shortens perceived time (Sawyer, Meyers, \& Huser, 1994, Experiments 2 and 4; Zakay, 1989, Experiment 3; Zakay, 1993c, Experiments 1, 2, and 3; Zakay \& Fallach, 1984, Experiment 1), although one study (Zakay \& Fallach, 1984, Experiment 3) obtained null results. Anagram problems produce a similar shortening of perceived time (DeWolfe \& Duncan, 1959; Sawyer et al., 1994, Experiments 1, 3, and 4), as do a wide variety of other verbal tasks, including proofreading (Brown \& Stubbs, 1992), judging rhyming patterns (Fortin \& Breton, 1995, Experiment 2), solving analogies (Axel, 1924), and verbal rehearsal (Miller, Hicks, \& Willette, 1978). Some researchers have compared time judgments of intervals spent performing easy versus difficult versions of such tasks, and the results show that the more difficult task is associated with shorter judgments (Block, 1992, Experiment 1; Harton, 1938a), although one study yielded an opposite effect (Martin, Shumate, \& Frauenfelder, 1981). Some experimental designs have included three or more task conditions representing different degrees of difficulty, and the results indicate that perceived time becomes progressively shortened as the task becomes more demanding (Smith, 1969; Zakay, Nitzan, \& Glicksohn, 1983). It should be noted, however, that one manipulation that does not seem to interfere reliably with prospective timing is depth of processing. In this task, subjects must respond to either the structural features of words (shallow processing) or the semantic aspects of the words (deep processing). Although McClain (1983) found evidence that deeper processing was associated with shorter and more inaccurate time judgments, other studies have found either no effect (Block, 1992, Experiment 2) or an ambiguous pattern (Martinez, 1992, 1994).

Many researchers have employed a variety of information-processing tasks emphasizing cognitive effort, short-term memory, and mental operations. Although Essman (1958) found that a problem-solving task lengthened perceived time, most other studies report that effortful cognitive tasks shorten perceived time. For example, intervals spent performing demanding attentional tasks (Brown, 1985, Experiment 2; Tsao, Wittlieb, Miller, \& Wang, 1983) or memory tasks (Fortin \& Breton, 1995, Experiment 1; Hicks \& Brundige, 1974) are associated with a shortening of perceived time and/or more error in time judgments relative to control conditions. Fortin and colleagues (Fortin \& Rousseau, 1987; Fortin et al., 1993, Experiment 1) studied memory search tasks and found that the more mental comparisons required, the progressively shorter the perceived time (longer temporal productions).

Two particular cognitive tasks have been used in several timing studies. One task involves manipulations of response uncertainty, which is usually accomplished by having subjects sort playing cards into a single stack ( 0 bits of information per card), two stacks based on color ( 1 bit of information), or four stacks based on suit ( 2 bits of information). Conditions involving more response uncertainty (i.e., more bits of transmitted information) are judged to be shorter than control (no-sorting) or singlestack sorting conditions (Allen, 1980; Zakay, 1992, Experiment 1). Hicks and colleagues (Hicks et al., 1977; Hicks, Miller, \& Kinsbourne, 1976) obtained linear decreases in time judgments (verbal estimates) as a function of increased response uncertainty. The one exception to this pattern was reported by Michon (1965), who employed a choice response task involving pointers occupying different positions on dial faces; he found that greater response uncertainty lengthened perceived time (shorter temporal productions). The other cognitive task used in many studies is mental arithmetic. Most experiments comparing control (no-task) versus mental arithmetic conditions find that the task reliably shortens perceived time (Burnside, 1971; Gulliksen, 1927; Hawkes, 1972; Hawkes \& Sherman, 1972; Wilsoncroft \& Stone, 
1975). Time judgments also may become more inaccurate under arithmetic conditions than under control conditions (Marmaras, Vassilakis, \& Dounias, 1995). Wilsoncroft, Stone, and Bagrash (1978) manipulated task difficulty but found no difference between temporal judgments of easy and difficult (as defined by the magnitude of the digits employed) mental multiplication problems.

Thus, there is a substantial amount of empirical evidence showing that nontemporal tasks disrupt timingtypically, by shortening perceived time and, sometimes, by increasing time judgment variability. With some exceptions, increases in nontemporal task difficulty lead to a graded deterioration in timing performance. These effects are produced by an extraordinarily wide range of nontemporal tasks. Theoretical explanations for these effects emphasize limited-capacity attention, multitask time sharing, and the allocation of processing resources.

\section{Attentional Allocation Model}

A number of authors have argued that the interference effect can best be accounted for by an attentional allocation model (e.g., Brown, 1985; Brown \& West, 1990; Hicks et al., 1977; Hicks et al., 1976; Thomas \& Brown, 1974; Thomas \& Cantor, 1975, 1978; Thomas \& Weaver, 1975; Zakay, 1989, 1993a). In this view, temporal processing requires attentional resources. The more attention devoted to time, the greater the lengthening of perceived duration, perhaps because additional resources enhance the accumulation of temporal cues in a cognitive timer mechanism. Nontemporal tasks draw processing resources away from timing. A person trying to keep track of time while simultaneously performing a demanding cognitive task is placed in a dual-task situation, in which resources must be shared between temporal and nontemporal processing. Fewer resources allocated to timekeeping disrupt the accumulation of cues in the timer. Many cues are not fully processed or are missed entirely, resulting in an internal temporal record that is incomplete, unreliable, and full of gaps. Time judgments, based on this record, are correspondingly inaccurate. These judgments often show that perceived time is shortened, an effect that may reflect the overall reduction in the number of stored temporal cues. In some cases, time judgments exhibit more variability or absolute error (both underestimations and overestimations). These responses represent an instability in temporal processing and point to a large element of error, uncertainty, and guessing in subjects' judgments.

The model has prompted new approaches to the study of attentional resources in time perception. In the multiple timing procedure (Brown \& West, 1990), subjects must attend to multiple independent, overlapping temporal events and judge the duration of one of those events chosen at random. The reasoning is that two or more concurrent temporal tasks should compete for processing resources and interfere with one another. A series of studies involving various time judgment methods and response measures showed that temporal judgments became more inaccurate and variable under multiple tim- ing conditions and that greater numbers of temporal events produced a progressive deterioration in time judgment performance (see Brown, Stubbs, \& West, 1992; Brown \& West, 1990). In the attentional sharing procedure, subjects are instructed to devote specified amounts of attention to concurrent temporal and nontemporal tasks (e.g., $75 \%$ of attention to time and $25 \%$ to the nontemporal task). A number of studies have shown that time judgments become increasingly inaccurate (a reduction in temporal sensitivity as measured by $d^{\prime}$ ) as less attention is allocated to timing (see Casini et al., 1992; Grondin \& Macar, 1992; Macar et al., 1994).

Hence, the attentional allocation model provides a clear and straightforward account of the interference effect. The model also is consistent with experiments involving more direct manipulations of attention to time. However, one important issue has been ignored in most previous research. This issue involves performance on the nontemporal task and the notion of bidirectional interference.

\section{Bidirectional Interference}

If the attentional model is correct in assuming that temporal and nontemporal tasks compete for processing resources, then it is reasonable to expect that the pattern of interference would be bidirectional. That is, if attentional resources must be shared between two tasks, then each task receives a reduced (and, presumably, less than optimal) amount of attention. It follows that if nontemporal processing interferes with timing, then timing should interfere with nontemporal processing. A clear demonstration of bidirectional interference between temporal and nontemporal tasks would provide strong support for the attentional allocation model. Despite its theoretical importance, however, research in this area is sparse. There are two main problems. These problems also exist in other studies based on the dual-task paradigm (see Kinsbourne \& Hiscock, 1983, p. 323). First, researchers usually do not measure nontemporal task performance. The focus is centered primarily on temporal judgments, and the nontemporal task is viewed simply as a means of distracting subjects from time. The second problem is an experimental design problem. Most studies do not include a control condition in which the nontemporal task is performed alone, without any requirement to judge time. This condition is critical for evaluating the resource demands of timing.

A few studies are free of these problems. Thomas and Cantor (1975) presented tachistoscopic displays of circles to subjects under three conditions: judge time only, judge size only, and mixed (judge either time or size). The results showed that time judgments were equivalent under time and mixed conditions, whereas size judgments declined from size to mixed conditions. A later study (Thomas \& Cantor, 1978) involving a letter detection task found the reverse pattern, with a reduction in time judgment accuracy from time to mixed conditions, but no change in letter detection accuracy under the detection and mixed conditions. Two studies using the attentional sharing procedure (Macar et al., 1994, Experiments 2 
and 3) found interference for time judgments, but not for the nontemporal task. However, other attentional sharing studies have reported clear evidence of performance tradeoffs between timing and various concurrent nontemporal tasks, including loudness judgments (Grondin \& Macar, 1992), brightness judgments (Casini et al., 1992, Experiment 1), and word categorization (Macar et al., 1994, Experiment 1). Grondin and Macar (1992) argued that the bidirectional pattern of interference implied that the temporal and nontemporal tasks competed for a common set of processing resources.

Research from two other areas-human factors and manual tapping - also bear on the issue of bidirectional temporal/nontemporal interference. Many investigators in human factors are concerned with mental workload in complex multitask environments, and some of this research involves concurrent temporal and nontemporal tasks (see Eggemeier \& Wilson, 1991, pp. 224-228). The usual procedure is to test subjects on a complex primary task with different degrees of difficulty and measure performance on various concurrent secondary tasks. Often, an intrusion analysis is applied to primary task performance to assess "artifactual" effects attributable to the secondary tasks. This analysis is important in the present context, because it may reveal bidirectional interference between temporal and nontemporal tasks. Several studies using a flight simulator as the primary task and temporal production as a secondary task have found that timing responses become more variable as the flight task becomes more difficult, but that flight performance itself is unaffected by concurrent timing (Bortolussi, Kantowitz, \& Hart, 1986; Casali \& Wierwille, 1983, 1984; Wierwille \& Connor, 1983). One study (Wierwille, Rahimi, \& Casali, 1985) did find a pattern of bidirectional interference. The primary task in this case involved manipulations of navigational workload, a task that relies heavily on mathematical problem solving. Time judgments showed a linear increase in variability as the navigational task became more difficult. An intrusion analysis revealed that concurrent timing increased the error rate on the navigational task, relative to no-timing control conditions.

Research involving manual tapping also relates to the issue of bidirectional interference. In this task, subjects must generate a regular series of rapid tapping responses (ranging from one or two taps per second to tapping as fast as possible). Although often described as a manual or motor task (e.g., Kinsbourne \& Hiscock, 1983), the task is also a timing task involving short temporal productions. The task is employed frequently in dual-task experiments exploring cerebral asymmetry, task compatibility, and resource demands. Several researchers have shown that the addition of various concurrent tasks increases the variability of tapping responses (Klapp, 1981; Michon, 1966; Nagasaki, 1990), an outcome that corresponds to the interference effect in timing. In some experiments, researchers have carefully measured both tapping and nontapping performance under single- and dual-task conditions. Some studies have found interference in tapping performance only (Bathurst \& Kee,
1994; Kantowitz \& Knight, 1976, Experiment 1; Kee, Morris, Bathurst, \& Hellige, 1986). However, other studies have uncovered evidence of bidirectional interference between tapping and concurrent mental arithmetic tasks (Kantowitz \& Knight, 1974; Kantowitz \& Knight, 1976, Experiment 2; Klapp, Porter-Graham, \& Hoifjeld, 1991) and reading tasks (Hiscock, Cheesman, Inch, Chipuer, \& Graff, 1989).

The findings on bidirectional interference are mixed. Of the 18 studies reviewed above that have examined both temporal and nontemporal performance, 7 reported bidirectional interference, 10 reported interference in timing performance only, and 1 reported interference in nontemporal performance only. These studies differ considerably in terms of temporal and nontemporal tasks, durations, response measures, and so on. What is needed is a more systematic examination of different nontemporal tasks within a common methodological framework.

\section{THE PRESENT RESEARCH}

The present research consists of three experiments designed to measure performance on concurrent temporal and nontemporal tasks. The tasks were performed on a continuous basis across a series of 2 -min trials. This procedure creates a reasonably large performance "window" in which to examine any potential interference effects, yet it is small enough to minimize fatigue. Continuous, self-paced tasks were chosen because they provide steady state (as opposed to transient) measures of resource availability (see Gopher, 1986). The experimental design also included single- and dual-task conditions for both the temporal and the nontemporal tasks. The attentional allocation model assumes that temporal and nontemporal tasks draw from the same limited pool of processing resources. Therefore, simultaneous temporal and nontemporal processing should produce mutual interference due to resource competition.

\section{General Method}

Timing task. The timing task was designed to minimize the role of episodic, long-term memory and reconstructive processes in time judgments and to maximize the role of short-term, working memory and attentional resources. Consequently, subjects judged relatively short durations ( 2 and $5 \mathrm{sec}$ ); two durations were used to test the generality of the findings. The task was to produce a series of these durations by pressing a response key repeatedly as the trial progressed. Thus, subjects generated a series of short temporal productions, providing a continuous "on-line" measure of timing throughout the task interval. One important aspect of this methodology is that temporal productions bear an inverse relationship to verbal estimations and reproductions (Doob, 1971, pp. 27-29; Fraisse, 1978, pp. 215-217). With verbal estimations and reproductions, subjects judge an interval defined by the experimenter. If conditions during the interval cause a reduction in the number of temporal cues perceived, subjects may be biased to judge the interval as having been relatively short. In contrast, the production method requires that subjects generate a specified interval. If the prevailing task conditions reduce the number or salience of temporal cues, then the subject may allow a relatively longer amount of time to pass by before he or she judges that the interval has elapsed. Hence, the same set of experimental condi- 
Table 1

Outline of Task Conditions for Sessions 1 and 2

Session 1: Single-Task Conditions

2-sec Timing

5-sec Timing

Easy nontemporal task

Difficult nontemporal task

Session 2: Dual-Task Conditions

2 -sec Timing + Easy task

2-sec Timing + Difficult task

5-sec Timing + Easy task

5-sec Timing + Difficult task

tions results in shorter verbal estimations and reproductions, yet longer productions. In both cases, perceived time is shortened (see Zakay, $1993 \mathrm{c}$, for an empirical comparison of these methods in the context of the interference effect). Therefore, to be consistent with previous work, one would expect temporal productions to become longer (and/or more variable) in the presence of interfering nontemporal task demands.

Nontemporal tasks. Each of the three experiments involved a different nontemporal task. Selection of the tasks was based on several important considerations. First, task performance had to be compatible with the ongoing nature of the concurrent timing task. This provision limited the choices to tasks that could be performed in a continuous, uninterrupted fashion with a single hand. Second, the nontemporal tasks were required to be capacityconsuming tasks that could be manipulated to produce different degrees of difficulty. Research on the interference effect suggests that time judgment performance should deteriorate as a function of increasing nontemporal task demands. A third requirement was that the nontemporal tasks be associated with an established body of research. A preexisting literature provides a set of standardized methods and response measures, as well as a theoretical context for the nontemporal task. Finally, the tasks were selected to reflect the wide range of nontemporal tasks that have produced the interference effect. The tasks chosen represented three broad areas: motor, perceptual, and cognitive. Experiment 1 (motor) involved pursuit rotor tracking, Experiment 2 (perceptual) involved a visual search task, and Experiment 3 (cognitive) involved mental arithmetic. The attentional allocation model assumes that timing diverts resources from the nontemporal task, and so should produce a deterioration in nontemporal performance.

Procedure. The same general methodology was used in all three experiments. Each subject was tested in each condition on two different sessions. Table 1 outlines the structure of the experiments. Session 1 involved single-task (control) conditions, and it was designed to obtain baseline performance measures on the timing tasks and nontemporal tasks. Each condition included four 2 min trials. In the $2-\sec$ timing condition, the subject generated a continuous series of 2 -sec temporal productions during each 2min trial. In the 5-sec timing condition, the subject generated a series of 5-sec productions on each trial. The easy nontemporal task condition refers to a relatively easy version of the nontemporal task employed in a given experiment; the difficult nontemporal task condition represents a more demanding version of the task. Session 2 involved the dual-task conditions, in which the subjects performed the temporal and nontemporal tasks concurrently. As in Session 1, the subjects were tested in each condition for four 2-min trials. The subjects were instructed to regard the temporal and nontemporal tasks as being equally important. The structure of the experiments allows a comparison of timing performance under control conditions (with no distractions) and when one is also engaged in a demanding nontemporal task. The same situation applies to nontemporal task performance, with comparisons made between the nontemporal task alone (control condition) versus the nontemporal task performed with a concurrent timing task.

\section{EXPERIMENT 1 Pursuit Rotor Tracking}

The nontemporal task used in Experiment 1 was pursuit rotor tracking. The task requires subjects to manually follow a continuously moving visual target. The emphasis is on motor control and perceptual-motor coordination. The pursuit rotor has been characterized as "a demanding and compelling task" (Bacon, 1974, p. 86), and task difficulty may be manipulated by varying the target speed. The standard measure of task performance is the amount of time the subject maintains contact with the target. Much of the research involving the pursuit rotor is concerned with skill acquisition and learning curves, but several studies have explored processing resources in tracking via the dual-task paradigm.

\section{Pursuit Rotor and Dual-Task Performance}

Some investigators have focused on the effects of potentially interfering secondary tasks on the primary task of pursuit rotor tracking. Bell (1978) found that a concurrent number-processing task had no effect on pursuit rotor performance. In contrast, two studies (Bacon, 1974; Mastroianni \& Schopper, 1986) examined the effects of concurrent auditory attention tasks, and both found that the tasks reduced tracking performance, relative to control conditions involving the pursuit rotor alone. Other investigators have considered the concurrent nontracking task to be the primary task of interest. In some studies, subjects attempt to learn or recall word lists while simultaneously performing pursuit rotor tracking. The usual result is that memory performance is worse under dual-task conditions than under single-task memoryonly conditions (Baddeley, Grant, Wight, \& Thomson, 1975, Experiment 3; Baddeley \& Lieberman, 1980, Experiment 5; Watkins, Watkins, Craik, \& Mazuryk, 1973). Watkins et al. (1973) argued that even though the pursuit rotor task is nonverbal, it is sufficiently demanding to divert attentional resources from verbal processing.

Some dual-task studies have used memory tasks emphasizing either verbal or visual processing. These studies are important because the researchers were interested in bidirectional patterns of interference. The results show that the pursuit rotor interferes more with visual memory than with verbal memory (Baddeley et al., 1975, Experiment 2; Baddeley \& Lieberman, 1980, Experiments 3 and 4; Warren, 1977, Experiments 1 and 2). Interestingly, the interference effect here is asymmetrical, with no difference found between the memory conditions in terms of pursuit rotor tracking performance. One exception is reported by Baddeley et al. (1975, Experiment 1), where the visual task produced a decrement 
in pursuit rotor performance, relative to the verbal and control (no memory task) conditions. However, memory performance was not affected by tracking.

In sum, pursuit rotor tracking is a resource-demanding task emphasizing motor and spatial processes. The task is well suited for the present research, since it may disrupt (or be disrupted by) various concurrent tasks. To the extent that attentional resources are shared between the two tasks, one may expect interference between concurrent timing and pursuit rotor tracking.

\section{Method \\ Subjects. Thirty-one introductory psychology students (12 males, 19 females) from the University of Southern Maine served as volunteer subjects. The students ( $M$ age $=26.0$ years) received extra course credit for their participation. \\ Apparatus and Stimuli. An Apple Ilgs computer equipped with a mouse device and a Timemaster II H. O. clock card (Ap- plied Engineering) set at an interrupt rate of $1024 \mathrm{~Hz}$ was pro- grammed to time the trials and to monitor time judgment re- sponses. A photoelectric rotary pursuit apparatus (Lafayette Model 30013) was used for tracking. The apparatus was fitted with a triangular template measuring $22 \mathrm{~cm}$ per side, with a 1.8 - $\mathrm{cm}$-wide pathway for a moving target light. A triangular path is particularly demanding because the target changes in direction and speed as it moves around the corners (Frith, 1971; Jensen, 1975; Whitehurst \& Del Rey, 1983). A hand-held photosensitive stylus was used to track the target. Contact with the target accu- mulated time on a stop clock (Lafayette Model 58007).}

Design and Procedure. The subjects were tested individually in two sessions, each lasting less than $1 \mathrm{~h}$. The sessions were separated by at least 2 weeks in order to minimize any potential carryover practice effects. The four trials associated with each task were separated by approximately $2 \mathrm{~min}$. Watches were removed prior to testing. For the timing tasks, the subjects held the computerlinked mouse in their nonpreferred hand and pressed the response button at a steady rate of once every 2 or $5 \mathrm{sec}$ (depending on the task condition) throughout the 2-min interval of each trial. The computer emitted a beeping sound to signal the end of the trial. The easy and difficult versions on the tracking task corresponded to target speeds of 20 and $35 \mathrm{rpm}$, respectively. The target moved in clockwise and counterclockwise directions on alternate trials. The subjects always tracked the target with the stylus held in their preferred hand. The four tasks of Session 1 (single-task control conditions)-2-sec timing, 5-sec timing, 20-rpm tracking, and 35rpm tracking - were ordered randomly on an individual basis for each subject. In Session 2 (dual-task conditions), the four combinations of the timing and tracking tasks were also ordered randomly for each subject. The one restriction in randomization was that each possible sequence of the four tasks in each session was employed at least once and not more than twice. The subjects were instructed to give equal priority to the timing and tracking tasks.

\section{Results and Discussion}

Three measures of timing performance and one measure of tracking performance were evaluated.

Timing performance. The timing data were cast in the form of a $2 \times 3 \times 4$ repeated measures analysis of variance (ANOVA). The factors were timing ( 2 and $5 \mathrm{sec}$ ), tracking (no tracking control, slow tracking, and fast tracking), and trials (Trials 1-4). Timing performance was measured in terms of mean temporal production scores, the standard deviation $(S D)$ of the temporal productions, and the coefficient of variation.
Mean temporal production. The mean temporal production generated by each subject in each condition was computed; these scores reflect any overall lengthening or shortening of perceived time. The ANOVA disclosed a significant main effect for timing $[F(1,30)=252.71$, $p<.001]$, which showed that the subjects generated shorter intervals in the $2-\mathrm{sec}$ condition $(M=2.0 \mathrm{sec})$ than in the 5 -sec condition $(M=4.5 \mathrm{sec})$. This result simply confirms that the subjects were following instructions appropriately. The main effect for trials $[F(3,90)=14.63$, $p<.001]$ is compounded by the timing $\times$ trials interaction $[F(3,90)=6.40, p<.001]$. Simple main effects tests contrasting the trials within each timing condition showed that the productions did not change across trials in the 2-sec condition $(F<1)$, but they steadily increased in the 5 -sec condition $[F(3,90)=11.77, p<.001]$. In this case, the mean temporal productions for Trials 1, 2, 3, and 4 were $4.3,4.6,4.6$, and $4.7 \mathrm{sec}$, respectively. A trend analysis conducted on these scores showed that the linear component was significant $[F(1,30)=18.47, p<$ .001 ], accounting for $88.5 \%$ of the variance. None of the other effects in the ANOVA were significant.

Standard deviation. Given that the subjects generated a fairly large number of temporal productions on each trial, the data provide an ideal opportunity for an analysis of timing variability. Several studies (e.g., Brown \& West, 1990; Goldstone, 1975; Guay \& Salmoni, 1988) indicate that $S D$ scores and other variability measures may be very sensitive at detecting perturbations in timing. The $S D$ of the temporal productions in each condition was calculated for each subject. These scores indicate how consistent the subjects were in their time judgment responses. The SDs were submitted to the ANOVA, and the main effect for timing was significant $[F(1,30)=101.84$, $p<.001]$. The 2 -sec intervals $(M=0.43 \mathrm{sec})$ had smaller $S D$ s than did the 5 -sec intervals $(M=0.87 \mathrm{sec})$. This effect, of course, is influenced by the lengths of the two target durations, and so it must be interpreted with caution. The main effect for tracking $[F(2,60)=36.45, p<$ $.001]$ and the timing $\times$ tracking interaction $[F(2,60)=$ $9.06, p<.001]$ are less ambiguous. The interaction is ordinal with respect to tracking (see Keppel, 1982, pp. 211-212), and so the main effect may be interpreted without qualification: Timing became increasingly variable from control $(M=0.34 \mathrm{sec})$ to slow $(M=0.76 \mathrm{sec})$ to fast $(M=0.84 \mathrm{sec})$ tracking conditions. This result shows a steady increase in timing variability as a function of nontemporal task demands. The timing $\times$ tracking interaction was subjected to simple main effects tests, which revealed that the tracking conditions exerted significant effects in both the 2-sec $[F(2,60)=28.74, p<$ $.001]$ and the $5-\sec [F(2,60)=26.66, p<.001]$ timing conditions. These effects were probed with a set of orthogonal comparisons: Contrast 1 (control vs. slow plus fast) compared single- and dual-task conditions, and Contrast 2 (slow vs. fast) compared the easy and difficult versions of the task. Contrast 1 was significant for both the $2-\sec [F(1,30)=38.76, p<.001]$ and the $5-\mathrm{sec}$ $[F(1,30)=54.93, p<.001]$ conditions. Contrast 2 was 


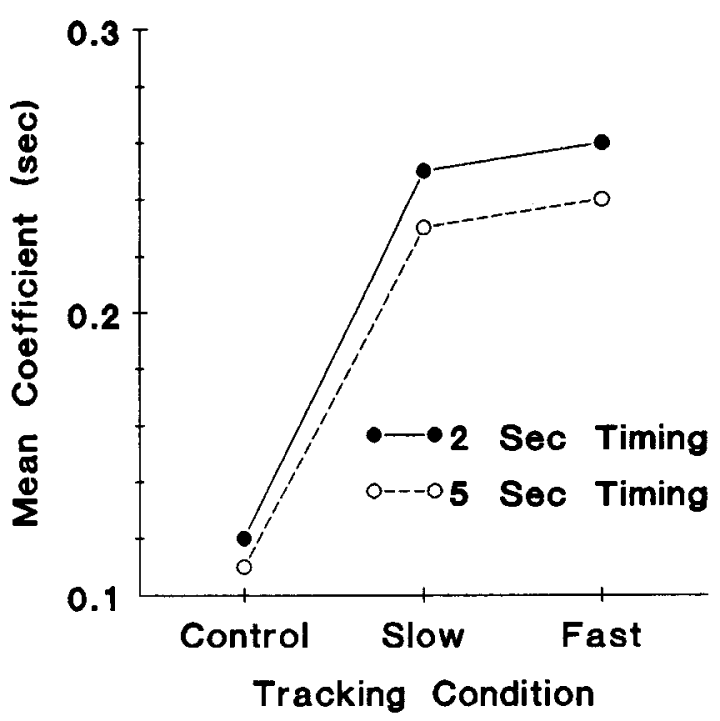

Figure 1. Mean coefficient of variation scores in time judgments for 2- and 5-sec timing conditions as a function of tracking condition in Experiment 1.

not significant in either case. None of the other effects in the ANOVA were significant.

Coefficient of variation. The $S D$ is an absolute measure of variability; however, because the subjects were asked to judge two different durations, it is appropriate also to analyze a relative measure of timing variability. The most common such measure is the coefficient of variation, given by dividing the $S D$ by the mean (e.g., Spiegel, 1961,p. 73, p. 84). Coefficients were computed for each subject in each condition and were submitted to the ANOVA. All three main effects were significant. The effect for timing $[F(1,30)=12.75, p<.001]$ showed that variability was relatively greater in the 2 -sec condition $(M=0.21 \mathrm{sec})$ than in the 5 -sec condition $(M=0.19 \mathrm{sec})$. Note that this outcome is opposite to that found in the $S D$ analysis. The main effect for tracking $[F(2,60)=$ $57.52, p<.001]$ is reflected in the mean scores for the three conditions: control $(M=0.11 \mathrm{sec})$, slow $(M=$ $0.24 \mathrm{sec})$, and fast $(M=0.25 \mathrm{sec})$ (see Figure 1). The same orthogonal comparisons as used previously were applied to these data. Contrast 1 (control vs. slow plus fast) was significant $[F(1,30)=72.54, p<.001]$; Contrast 2 (slow vs. fast) was not significant $(F<1)$. The main effect for trials was significant $[F(3,90)=4.33$, $p<.01]$. The mean coefficients for Trials $1,2,3$, and 4 were $0.22,0.19,0.20$, and $0.20 \mathrm{sec}$, respectively. Trend analyses applied to these scores showed a significant quadratic component $[F(1,30)=6.28, p<.02]$, accounting for $28.6 \%$ of the variance, and a significant cubic component $[F(1,30)=6.43, p<.02]$, accounting for $42.8 \%$ of the variance. Thus, variability decreased substantially from Trial 1 to Trial 2, but then increased somewhat for Trials 3 and 4 . These results may represent the effects of initial task familiarization and later fatigue on performance. None of the other effects in the ANOVA were significant.
Tracking performance. The traditional measure of pursuit rotor tracking performance is the total time on target (TOT) - that is, the amount of time the subject keeps the stylus in contact with the target light. Some pursuit rotor systems are configured to derive other measures of tracking performance, such as the number of stylus-target contacts, the duration of contacts, the distribution of contacts, and so on. But other than identifying different tracking styles, these indices do not appear to add much information to that gathered by the more conventional TOT measure (see Ammons, 1951, Frith, 1971, and Siegel, 1990, for comparative analyses of such measures).

The TOT for each 2-min trial was used as the dependent variable in the analysis of tracking performance. These scores were submitted to a $2 \times 3 \times 4$ repeated measures ANOVA. The factors were tracking (slow and fast), timing (no timing control, 2-sec timing, and 5-sec timing), and trials (Trials 1-4).

Both the main effect for tracking $[F(1,30)=335.92$, $p<.001]$ and the tracking $\times$ timing interaction $[F(2,60)=$ $17.29, p<.001]$ were significant. The interaction is ordinal with respect to tracking, and so the main effect may be unambiguously interpreted: TOT for the slow condition $(M=53.61 \mathrm{sec})$ was nearly double that of the fast condition $(M=27.50 \mathrm{sec})$. This result confirms that the two conditions differed in terms of difficulty level. The interaction was analyzed with simple main effects tests contrasting the three timing conditions within each tracking condition; only the effect involving fast tracking was significant $[F(2,60)=26.42, p<.001]$. This effect was probed further with the same orthogonal comparisons used before. Contrast 1 (no timing control vs. combined 2- and 5-sec timing) was significant $[F(1,30)=$ $37.44, p<.001]$. The mean scores were $24.05 \mathrm{sec}$ (control condition) and $29.23 \mathrm{sec}$ (combined timing conditions). Note that the addition of a concurrent timing task actually led to an improvement in tracking performance. Contrast 2 (2-vs. 5-sec timing) was not significant $(F<1)$. The only other significant effect in the ANOVA was a main effect for trials $[F(3,90)=7.17, p<.001]$. The mean TOT scores for Trials $1,2,3$, and 4 were 39.74 , $39.86,41.01$, and $41.63 \mathrm{sec}$, respectively. A trend analysis confirmed that the effect is linear $[F(1,30)=16.82$, $p<.001]$, accounting for $92.8 \%$ of the variance.

Summary. The results of this experiment replicate other studies showing the interference effect in timing and extend the findings to a different set of temporal and nontemporal tasks. Both measures of timing variability were sensitive in detecting the detrimental effects of a concurrent nontemporal task, and one measure $(S D)$ showed a graded deterioration in timing as a function of nontemporal task difficulty. The temporal productions tended to become progressively longer across trials, a phenomenon called the lengthening effect, which has been observed in numerous studies in which subjects are required to produce a continuous series of tapping responses (e.g., Hicks \& Allen, 1979; Ross, 1969).

Analysis of tracking performance yielded a mixed set of results. Task performance increased linearly across 
the four trials, indicating improvement with practice. Comparisons of single-task (tracking only) versus dualtask (timing + tracking) conditions produced an unexpected pattern. TOT scores were the same under singleand dual-task conditions when the subjects tracked the slow target, but TOT scores were significantly higher under dual-task conditions when the subjects tracked the fast target. This result is at odds with a strict attentional allocation model. However, other research on dual-task performance suggests that this outcome may be an example of a concurrence benefit (Navon \& Gopher, 1979), in which a task may be performed better when conjoined with another task than when performed alone. The combination of template size $(22 \mathrm{~cm} /$ side $)$, target speed $(35 \mathrm{rpm})$, and temporal durations ( 2 and $5 \mathrm{sec}$ ) may have enabled the subjects to synchronize tracking with timing responses. A 2 -sec interval corresponds to approximately one complete circuit of the fast target around the triangular template (1.17 circuits exactly), and a 5 -sec interval corresponds to nearly three complete circuits (2.92 circuits exactly). The rhythmicity of the timing task may have facilitated tracking under dual-task, fasttarget conditions in an effect called rhythmic capture (Klapp et al., 1991, p. 158). The task dynamics were such that tracking the fast target could be coordinated with the timing responses, enabling the subject to more easily keep pace with the target. This integration of tasks would lead to less error in tracking performance. In a series of careful studies, Klapp $(1979,1981)$ has shown that interference between concurrent motor-response tasks is reduced if the two tasks are temporally compatible. In the present case, the timing task facilitated tracking performance, although the tracking task disrupted timing according to variability measures.

\section{EXPERIMENT 2 Visual Search}

Visual search was the nontemporal task in Experiment 2 . In its basic form, the task requires subjects to scan an array of distractor letters in search of a particular target letter (Neisser, 1963). Target detection performance is given by measures of response accuracy or response speed. The task has been used extensively in research on visual feature analysis and pattern recognition. The search literature includes a diverse set of paradigms, experimental findings, and theoretical models (e.g., Cheal \& Lyon, 1992; Duncan \& Humphreys, 1989, 1992; Fisher, Duffy, Young, \& Pollatsek, 1988; Palmer, Ames, \& Lindsey, 1993; Wolfe, 1994). Many issues are controversial and remain unresolved. One complication in interpreting the literature is that visual search involves multiple component processes. Some of these processes are preattentive and may operate in parallel, but other processes consume limited-capacity attention (Cheal \& Lyon, 1992; Czerwinski, Lightfoot, \& Shiffrin, 1992).

\section{Visual Search and Resource Demands}

Research on practice effects, target-distractor similarity, and dual-task performance highlights the involvement of processing resources in visual search. Many studies have shown that search performance improves with practice, eventually reaching the point where the task becomes automatized (Czerwinski et al., 1992; Healy, Fendrich, \& Proctor, 1990; Lajoy \& Seethoff, 1974; Neisser, 1963; Rabbitt, Cumming, \& Vyas, 1979; Schneider \& Fisk 1982a, 1982b; A. Treisman, Vieira, \& Hayes, 1992). Automatization refers to performing a highly practiced task with few or no processing resources. The development of automaticity implies that the task initially relied heavily on processing resources, but that this reliance diminished with practice and experience.

Another effect pointing to the involvement of processing resources in visual search concerns the physical similarity of the target and distractor stimuli. It is well established that search performance deteriorates as target-distractor similarity increases (Cheal \& Lyon, 1992; Corcoran \& Jackson, 1977; Duncan \& Humphreys, 1989; Eriksen \& Yeh, 1985; Neisser, 1963; Pashler, 1987; Wolfe, 1994). Highly similar stimuli force subjects to extract detailed information on distinctive features in order to discriminate between targets and distractors. This detailed analysis requires attentional resources, and the more confusable the stimuli, the greater the resource demand.

Visual search has also been used in the dual-task paradigm. Logan (1978) and Madden and Allen (1989) had subjects perform a primary visual search task concurrently with a secondary tone-detection task. Both studies found evidence of mutual interference between the two tasks: Visual search interfered with tone detection, and tone detection interfered with visual search. Schneider and Fisk (1982a) gave subjects extensive training on visual search tasks. When subjects were tested on two concurrent search tasks, there was a substantial criterion (beta) shift in search performance, with subjects becoming more conservative (i.e., adopting a stricter response criterion) in their judgments under dual-task conditions.

Thus, visual search is a perceptual task that is closely associated with attentional processes. It requires processing resources, and this demand can be manipulated experimentally. According to an attentional allocation model, interference should occur between concurrent visual search and timing tasks.

\section{Method}

Subjects. Thirty-three students ( 11 males, 22 females) from introductory psychology classes volunteered for the experiment in exchange for course credit. The mean age of the students was 27.8 years. None had participated in Experiment 1.

Apparatus and Stimuli. The computer hardware and software were the same as in Experiment 1. The subjects were required to scan an array of letters to find each occurrence of a particular target letter (the letter K). Easy and difficult versions of the task were created. In the easy condition, targets were intermixed with round 
distractors (the letters $\mathrm{C}, \mathrm{O}, \mathrm{Q}$, and $\mathrm{U}$ ). This procedure lessens processing demands by making the targets easily discernable from the distractors. In the difficult condition, targets were presented with angular distractors (the letters $\mathrm{V}, \mathrm{W}, \mathrm{X}$, and $\mathrm{Y}$ ). In this case, the similarity of features makes the targets more difficult to identify. On the basis of an empirical interletter confusion matrix for capital letters provided by van der Heijden, Malhas, and van den Roovaart (1984), the mean probability for confusing the target letter $\mathrm{K}$ with the round distractors is .004 , whereas the corresponding value for the angular distractors is .083 . The letters were typed on sheets of paper in uppercase, in a 12-characters-per-inch, fixed-width, elite font. Each sheet contained 26 lines of letters, and each line consisted of 40 letters with a space between each letter. A random number table was used to determine the sequence of letters, with each letter (the four distractors and the target) having an equal probability of occurring ( $p=.2$ ). The one restriction was that no more than three consecutive occurrences of the same letter were allowed.

Design and Procedure. The subjects were tested individually in two sessions, which were separated by at least 2 weeks. Each session lasted less than $1 \mathrm{~h}$. Session 1 consisted of four singletask conditions, and Session 2 consisted of four dual-task conditions. For the dual-task conditions, the subjects were told to consider both the timing and the search tasks to be equally important. Each condition included four 2-min trials, with each trial separated by approximately $2 \mathrm{~min}$. The timing tasks were the same as in Experiment 1: The subjects removed their watches and held the mouse in their nonpreferred hand while they pressed the response button every 2 or $5 \mathrm{sec}$, depending on the task condition. The search procedure followed that of Gordon (1968). The subjects held a red felt-tipped pen in their preferred hand. They were instructed to scan across each line of letters from left to right and to mark each target they encountered. They were told that both speed and accuracy were important. If a subject scanned through an entire sheet before the 2 -min trial ended, he or she was to immediately go to the next sheet of letters and continue the search. The subjects circled the last letter they examined when the trial ended. The four task conditions in each session were randomly ordered for each subject, with the restriction that each possible sequence occurred at least once and not more than twice.

\section{Results and Discussion}

Timing performance. The timing data were evaluated in a $2 \times 3 \times 4$ repeated measures ANOVA. The factors were timing ( 2 and $5 \mathrm{sec}$ ), search (no search control, round distractors, and angular distractors), and trials (Trials 1-4). The mean temporal productions, the $S D$ of the temporal productions, and the coefficient of variation were analyzed.

Mean temporal production. The mean productions were submitted to the ANOVA, and the three main effects and one interaction were significant. The main effect for timing $[F(1,32)=244.58, p<.001]$ indicated, as expected, that the subjects produced shorter intervals in the 2 -sec condition $(M=2.2 \mathrm{sec})$ than in the 5 -sec condition $(M=5.1 \mathrm{sec})$. The main effect for search $[F(2,64)=$ $7.91, p<.001]$ showed that the temporal productions grew steadily longer from the control $(M=3.3 \mathrm{sec})$ to the round distractor $(M=3.7 \mathrm{sec})$ to the angular distractor $(M=3.9 \mathrm{sec})$ conditions. These scores were probed with orthogonal comparisons. Contrast 1 (control vs. round plus angular) was significant $[F(1,32)=8.71, p<$ $.01]$, as was Contrast 2 (round vs. angular) $[F(1,32)=$
$4.75, p<.05]$. Thus, temporal productions became progressively longer with increases in nontemporal task demands. The main effect for trials $[F(3,96)=21.76, p<$ $.001]$ is compounded by the significant timing $\times$ trials interaction $[F(3,96)=4.32, p<.01]$. This interaction was analyzed with tests of simple main effects contrasting the trials within each timing condition. In the 2-sec timing condition $[F(3,96)=11.43, p<.001]$, temporal productions increased from Trial $1(M=2.1 \mathrm{sec})$ to remain steady in Trial $2(M=2.2 \mathrm{sec})$, Trial $3(M=$ $2.2 \mathrm{sec})$, and Trial $4(M=2.2 \mathrm{sec})$. In the 5 -sec timing condition $[F(3,96)=14.27, p<.001]$, productions showed a more consistent increase from Trial $1(M=$ $4.8 \mathrm{sec})$ to Trial $2(M=5.0 \mathrm{sec})$, Trial $3(M=5.2 \mathrm{sec})$, and Trial $4(M=5.2 \mathrm{sec})$. A trend analysis confirmed that this increase is linear $[F(1,32)=17.29, p<.001]$, accounting for $86.5 \%$ of the variance. None of the other effects in the ANOVA achieved significance.

Standard deviation. The $S D$ scores derived from the temporal productions generated by each subject in each condition were submitted to the ANOVA. Significant effects were found for timing $[F(1,32)=71.51, p<.001]$, search $[F(2,64)=48.39, p<.001]$, and the timing $\times$ search interaction $[F(2,64)=10.17, p<.001]$. The interaction is ordinal with respect to both main effects, allowing the main effects to be interpreted without qualification. The effect for timing indicated that responses were less variable in the $2-\mathrm{sec}$ condition $(M=0.45 \mathrm{sec})$ than in the 5 -sec condition $(M=0.98 \mathrm{sec})$. The effect for search showed that variability increased as the task became more demanding: The mean $S D$ s for the control, round distractor, and angular distractor conditions were $0.38,0.83$, and $0.90 \mathrm{sec}$, respectively. The timing $\times$ search interaction was subjected to simple main effects tests contrasting the three search conditions within each timing condition. Both the 2-sec timing $[F(2,64)=43.08$, $p<.001]$ and the 5-sec timing $[F(2,64)=30.75, p<.001]$ tests were significant; orthogonal contrasts were applied to these data. Turning first to the $2-\mathrm{sec}$ condition, Contrast $1[F(1,32)=60.98, p<.001]$ confirmed a significant increase in variability from the control $(M=$ $0.24 \mathrm{sec}$ ) to the combined round and angular distractor conditions $(M=0.55 \mathrm{sec})$. Contrast 2 (round vs. angular) was not significant $(F<1)$. A similar pattern was found in the 5-sec condition: Contrast $1[F(1,32)=50.04, p<$ $.001]$ showed that variability increased from the control $(M=0.52 \mathrm{sec})$ to the combined round and angular search conditions $(M=1.18 \mathrm{sec})$, whereas Contrast 2 was not significant. None of the other effects in the ANOVA were significant.

Coefficient of variation. Coefficient of variation scores were submitted to the ANOVA, and the main effect for search was significant $[F(2,64)=148.72, p<.001]$ (see Figure 2 ). The mean coefficients associated with the control, round distractor, and angular distractor conditions were $0.11,0.22$, and $0.23 \mathrm{sec}$, respectively. Orthogonal comparisons disclosed a significant difference for Contrast 1 (control vs. round plus angular) $[F(1,32)=$ 


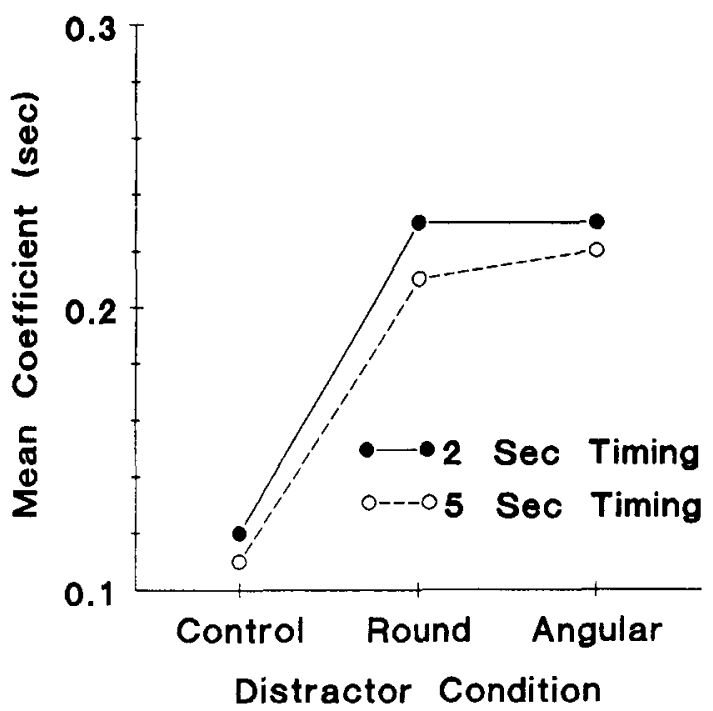

Figure 2. Mean coefficient of variation scores in time judgments for 2- and 5-sec timing conditions as a function of search (distractor) condition in Experiment 2.

$251.85, p<.001]$. Contrast 2 (round vs. angular) was not significant $(F<1)$. None of the other effects in the ANOVA achieved significance.

Search performance. Three measures of visual search performance were analyzed: characters scanned per second, target detection sensitivity, and target detection response bias.

Characters per second. The number of characters scanned per second is a basic performance measure of visual search efficiency. These scores were calculated for each 2 -min trial and submitted to a $2 \times 3 \times 4$ repeated measures ANOVA. The factors were search (round distractors and angular distractors), timing (no timing control, 2-sec timing, and 5-sec timing), and trials (Trials $1-4)$. The main effect for search $[F(1,32)=192.01, p<$ $.001]$ showed, as predicted, that the subjects scanned more characters among the round distractors $(M=7.18)$ than among angular distractors $(M=5.60)$. The main effect for trials $[F(3,96)=9.58, p<.001]$ indicated that the scanning rate increased from Trial $1(M=6.29)$ to Trial 2 $(M=6.49)$, Trial $3(M=6.44)$, and Trial $4(M=6.45)$. However, both this effect and the search $\times$ trials effect $[F(3,96)=6.40, p<.001]$ are subsumed under the timing $\times$ search $\times$ trials interaction $[F(6,192)=3.63, p<$ $.01]$. The three-way interaction was first probed with tests of simple interaction effects designed to evaluate the search $\times$ trials interaction within the three timing (control, 2-sec, and 5-sec) conditions. These tests disclosed that the only significant effect was associated with the 2-sec timing condition $[F(3,96)=10.55, p<$ $.001]$. Tests of simple, simple main effects revealed that the source of the interaction involved the round distractors $[F(3,96)=9.10, p<.001]$. The subjects in this case increased their mean rate of scanning from 6.69 to 7.02 to 7.19 to 7.18 characters per second for Trials $1,2,3$, and 4, respectively. Comparisons of the angular distractors across the four trials in the 2 -sec condition showed no comparable increase.

$A^{\prime}$ sensitivity index. The search task may be regarded as a signal detection problem (see Wolfe, 1994, pp. 210 212 ). The subject is required to detect random signals (target letters) embedded in a noise background (distractor letters). This arrangement enables search performance to be assessed in terms of detectability and bias measures. A nonparametric index of perceptual sensitivity $\left(A^{\prime}\right)$ was computed for each subject using the formula provided by Grier (1971). ${ }^{1} A^{\prime}$ can range in value from .500 (completely insensitive) to 1.000 (perfect sensitivity). The data were collapsed across trials in order to provide an adequate number of hits and false alarms for the calculation of $A^{\prime}$. These scores were submitted to a $2 \times 3$ (search $\times$ timing) repeated measures ANOVA, and the main effect for search was significant $[F(1,32)=13.29$, $p<.001]$. This result parallels the analysis of search rate in showing that target detection sensitivity was greater for the round distractor condition $(M=.997)$ than for the angular distractor condition $(M=.994)$. However, neither the main effect for timing nor the interaction were significant.

$B^{\prime \prime}$ bias index. $B^{\prime \prime}$ is a nonparametric index of response bias that can range in value from -1.000 to +1.000 . Negative values indicate a tendency to respond "yes--I detect a signal" when one is uncertain; positive values indicate a tendency to respond "no-no signal." $B$ " scores were calculated for each subject with the formula given by Grier (1971). ${ }^{2}$ The mean value of $B^{\prime \prime}$ for the entire sample of subjects ${ }^{3}$ was positive $(+.691)$, indicating an overall bias to respond "no." This result is typical of signal detection experiments in which the probability of a signal is low; in the present case, $p$ (target) $=.2$. The $B^{\prime \prime}$ scores were submitted to a $2 \times 3$ (search $\times$ timing) repeated measures ANOVA, and the main effect for search was significant $[F(1,30)=5.59, p<.03]$. The angular distractors were associated with higher $B^{\prime \prime}$ values $(M=$ $+.746)$ than were the round distractors $(M=+.635)$. Thus, the subjects adopted a stricter response criterion (a relatively stronger bias to respond "no") when they searched through the more difficult array of distractors. This shift to a more conservative criterion with increased search task difficulty is similar to that reported by Schneider and Fisk (1982a). None of the other effects in the ANOVA were significant.

Summary. Summarizing the results of Experiment 2, all three measures of timing performance demonstrated a substantial interference effect. The temporal productions became progressively longer as nontemporal task demands increased from the control (no-search) to easy (round distractors) to difficult (angular distractors) conditions. In a similar fashion, the two variability measures ( $S D$ and coefficient of variation) showed a deterioration in timing performance from the control to the two search conditions (the differences between the easy and difficult versions of the task were in the right direction but were not significant). As in Experiment 1, the temporal 
productions showed a lengthening effect across trials. All three nontemporal performance measures indicated that the angular distractors were more difficult to process than the round distractors. The subjects were slower, less sensitive, and more conservative in their judgments when scanning the angular distractors than when scanning the round distractors. As in Experiment 1, increased task difficulty impaired both temporal and nontemporal performance. However, the indices of nontemporal task performance failed to uncover any detrimental effects of the concurrent timing task: The difference between singletask (search-only) versus dual-task (search + timing) conditions was not significant.

\section{EXPERIMENT 3 Mental Arithmetic}

The nontemporal task in Experiment 3 was a math verification task, in which subjects were presented with a series of subtraction problems and they attempted to identify the problems that had incorrect answers. Mental arithmetic has been used extensively in studies of concentration, distraction, and working memory (see Ashcraft, 1992, for a review). Task difficulty can be manipulated by varying the number or complexity of mental operations involved, such as "carrying" and maintaining partial results in memory (Hitch, 1978; Wanner \& Shiner, 1976). Much of the work in this area involves dual-task interference and the role of processing resources in mental arithmetic.

Mental Arithmetic and Processing Resources. Although some simple arithmetical processes may be partially automatized (Zbrodoff \& Logan, 1986), mental arithmetic is, for the most part, intentional, effortful, and resource demanding. The effortful nature of mental arithmetic is one reason why researchers have often used it as a loading or distractor task in dual-task studies. Mental arithmetic interferes with a broad range of processes, including perceptual reversals (Reisberg, 1983; Reisberg \& O'Shaughnessy, 1984), adaptation to distorted visual inputs (Redding \& Wallace, 1985), and recognition memory performance (Kellogg, 1985). Because the task interferes with so many different cognitive processes, some investigators maintain that mental arithmetic draws from a pool of nonspecific "task-general resources" (Reisberg, 1983, p. 967). Another view is that mental arithmetic interferes with the coordination of multiple tasks or inputs (McLeod, 1977; Redding \& Wallace, 1985). The idea is that mental arithmetic draws resources from a central executive processor or controller, which acts to coordinate information from different sources. As more processing resources are used by the arithmetic task, the coordinating function of the executive control deteriorates, and performance on the concurrent task is disrupted.

Some studies suggest that mental arithmetic also involves specific pools of processing resources. For example, mental arithmetic is especially disruptive for con- current verbal tasks - a result interpreted to mean that numerical processing relies on subvocalization, phonological coding, and other processes that require verbal resources (Jou \& Harris, 1992; Logie \& Baddeley, 1987; Stefurak \& Boynton, 1986). In other research, Wickens and Kessel (1980) had subjects perform a tracking task in which they either operated a joystick-controlled cursor to track a target light (manual condition) or monitored a computer-controlled cursor as it tracked the target (autopilot condition). This task was performed concurrently with either mental arithmetic or a manual stabilization task. The results showed that autopilot tracking was disrupted by mental arithmetic but not by manual stabilization, whereas manual tracking produced the opposite pattern. Wickens and Kessel argued that autopilot tracking and mental arithmetic compete for resources associated with perceptual and central processing, whereas manual tracking and the stabilization task both depend on response-based resources.

In most studies, mental arithmetic is used as a secondary interfering task, with the main focus on primary (non arithmetic) task performance. One exception is a study by Wanner and Shiner (1976), who emphasized both tasks. Subjects were interrupted while working on concurrent mental subtraction and verbal memory tasks. It was found that both mental arithmetic and recall performance declined as the interruption point moved closer to where the arithmetic problem imposed its greatest demands on memory (i.e., the point of maximum transient memory load). These results demonstrate a clear pattern of bidirectional interference between mental arithmetic and a concurrent verbal task.

Mental arithmetic offers many advantages as a task to be combined with timing. The task is cognitively demanding, and task difficulty can be readily manipulated. Theoretical work has been based on mental arithmetic performance under dual-task conditions. Insofar as timing requires processing resources-particularly, verbal or perceptual/central resources - then mental arithmetic and timing should produce bidirectional interference.

\section{Method}

Subjects. Thirty students ( 13 males, 17 females) enrolled in introductory psychology classes volunteered for the experiment and received course credit for their participation. The subjects' mean age was 25.1 years. None of the subjects had participated in Experiments 1 and 2 .

Apparatus and Stimuli. The computer hardware and software used to monitor trial durations and timing responses were the same as used in Experiments 1 and 2. The math task was performed on a self-paced, continuous basis. The subjects were presented with a series of subtraction problems typed on sheets of paper, with 108 problems per sheet ( 12 problems per line $\times 9$ lines). These problems were presented in a standard arithmetical format, in which one number (the minuend) was positioned above a second number (the subtrahend). Beneath the subtrahend was a short horizontal line segment, and below that was the answer (the difference between the two numbers). For all problems, the result was always a positive value ( 0 or greater). The targets to be detected were wrong answers, which deviated \pm 1 from the cor- 
rect answer. The targets were distributed randomly among the distractors (correct answers); the probability of a target was .2. Both easy and difficult versions of the math task were created. For the easy problems, the minuend consisted of a single random value ranging from 2 to 9 , and the subtrahend consisted of a single random value from 1 to 9 , which was always equal to or less than the minuend. For the difficult problems, the minuend consisted of a random two-digit value ranging from 10 to 99 , and the subtrahend was a single random value ranging from 1 to 9 . The difficult version of the task was considered to be more demanding, since many of these problems required mentally "borrowing" and "carrying" numbers and holding an intermediate result in working memory while the rest of the calculation was performed (see Hitch, 1978).

Design and Procedure. As in Experiments 1 and 2, the subjects were tested individually in two $\mathrm{l}$-h sessions separated by at least 2 weeks. The procedure was the same as before. Watches were removed prior to each session. In Session 1, the subjects were tested on four single-task conditions. Each task was performed for four 2-min trials, with each trial separated by approximately $2 \mathrm{~min}$. In the $2-$ and $5-\mathrm{sec}$ timing tasks, the subjects held the mouse in the nonpreferred hand while they pressed the button at what they judged to be a steady 2 - or 5-sec rate, respectively. The subjects were encouraged to be as accurate as possible in making these responses. In the easy and difficult math tasks, the subjects held a red felt-tipped pen in the preferred hand and marked each target they found with a slash. Second and third sheets were available if needed, and the subjects circled the last problem they had worked on when the trial ended. Both speed and accuracy on the math task were emphasized. In Session 2, the four combinations of timing and math were performed under dual-task conditions. The subjects were informed that both tasks were equally important. In each session, the order of conditions was determined randomly for each subject, with the restriction that each possible sequence of conditions was used at least once and not more than twice.

\section{Results and Discussion}

Timing performance. The timing data were structured in a $2 \times 3 \times 4$ repeated measures ANOVA, with the factors being timing ( 2 and $5 \mathrm{sec}$ ), math (no math control, easy, and difficult), and trials (Trials $1-4)$. As in Experiments 1 and 2, the mean temporal productions, the $S D$ of the productions, and the coefficient of variation were analyzed.

Mean temporal production. All three main effects were significant. The effect for timing $[F(1,29)=142.91$, $p<.001]$ showed that the subjects generated shorter intervals in the $2-\mathrm{sec}$ condition $(M=2.7 \mathrm{sec})$ than in the 5 sec condition $(M=5.2 \mathrm{sec})$. The main effect for math $[F(2,58)=4.87, p<.01]$ uncovered a steady increase in temporal productions from the control condition $(M=$ $3.5 \mathrm{sec})$ to easy condition $(M=4.0 \mathrm{sec})$ to difficult condition $(M=4.3 \mathrm{sec})$. Orthogonal comparisons were used to test for differences between means. Contrast 1 (control vs. easy plus difficult) confirmed that dual-task conditions lengthened productions $[F(1,29)=4.68, p<.05]$. Contrast 2 (easy vs. difficult) was also significant $[F(1,29)$ $=5.92, p<.02]$, showing that increasing nontemporal demands led to a corresponding increase in temporal productions. The main effect for trials $[F(3,87)=7.67$, $p<.001]$ revealed a consistent lengthening of temporal productions across the four trials; the mean productions for Trials $1,2,3$, and 4 were $3.7,3.9,4.0$, and $4.1 \mathrm{sec}$, respectively. However, this result must be interpreted in light of the significant timing $\times$ trials interaction $[F(3,87)$ $=3.70, p<.02]$. Simple main effects tests contrasting the trials within each timing condition revealed that the increase in temporal productions across trials just failed to achieve significance in the 2 -sec condition $(p<.06)$. The 5 -sec condition $[F(3,87)=7.05, p<.001]$ did produce a significant effect. The mean productions associated with Trials $1,2,3$, and 4 in this case were 4.9, 5.1, 5.4 , and $5.4 \mathrm{sec}$, respectively. A trend analysis of these scores showed that the linear component $[F(1,29)=$ $12.83, p<.001]$ accounted for $91.4 \%$ of the variance. None of the other effects in the ANOVA were significant.

Standard deviation. The $S D$ scores were submitted to the analysis, and the main effect for timing was significant $[F(1,29)=31.44, p<.001]$. As in Experiments 1 and 2 , the 2 -sec condition was associated with smaller $S D \mathrm{~s}(M=0.60 \mathrm{sec})$ than was the 5 -sec condition $(M=$ $1.35 \mathrm{sec})$. The main effect for math $[F(2,58)=14.85, p<$ $.001]$ revealed a progressive increase in variability from the control condition $(M=0.49 \mathrm{sec})$ to easy condition $(M=1.03 \mathrm{sec})$ to difficult condition $(M=1.38 \mathrm{sec})$. This effect, however, is compounded by the significant timing $\times$ math interaction $[F(2,58)=5.27, p<.01]$. Tests of simple main effects compared the three math conditions within each timing condition. Turning first to the 2-sec timing condition $[F(2,58)=13.99, p<.001]$, orthogonal contrasts showed a significant effect for Contrast 1 $[F(1,29)=19.50, p<.001]$ : Timing responses in the control condition $(M=0.27 \mathrm{sec})$ were less variable than those in the combined easy-plus-difficult conditions $(M=0.77 \mathrm{sec})$. Contrast 2 (easy vs. difficult) was not significant $(F<1)$. In the 5 -sec condition $[F(2,58)=$ $10.77, p<.001]$, both orthogonal contrasts achieved significance. Contrast $1[F(1,29)=19.14, p<.001]$ showed timing in the control condition $(M=0.71 \mathrm{sec})$ to be less variable than in the combined easy-plus-difficult conditions $(M=1.65 \mathrm{sec})$. Contrast $2[F(1,29)=5.17, p<.05]$ revealed that variability increased from the easy math condition $(M=1.30 \mathrm{sec})$ to the difficult condition $(M=$ $1.99 \mathrm{sec})$. The only other significant effect in the ANOVA was a main effect for trials $[F(3,87)=2.94, p<.05]$. The mean $S D$ s for Trials $1,2,3$, and 4 were $0.87,0.91,0.99$, and $1.09 \mathrm{sec}$, respectively. The linear increase in variability across trials $[F(1,29)=4.82, p<.05]$ accounts for $96.5 \%$ of the variance.

Coefficient of variation. Analysis of coefficient of variation scores showed that all three main effects were significant. The effect for timing $[F(1,29)=10.78, p<$ $.01]$ indicated that timing in the 2 -sec condition $(M=$ $0.20 \mathrm{sec}$ ) was less variable than in the 5 -sec condition $(M=0.23 \mathrm{sec})$. The main effect for math $[F(2,58)=$ $43.40, p<.001]$ showed a progressive increase in variability as a function of task demands (see Figure 3 ). The mean coefficients for the control, easy, and difficult math conditions were $0.13,0.24$, and $0.26 \mathrm{sec}$, respectively. Contrast 1 (control vs. easy plus difficult) was sig- 


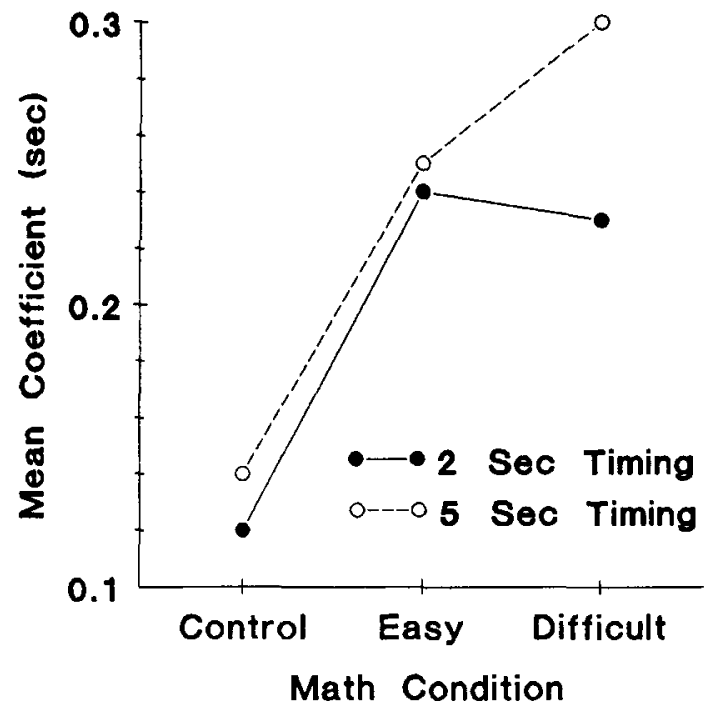

Figure 3. Mean coefficient of variation scores in time judgments for 2- and 5-sec timing conditions as a function of math condition in Experiment 3.

nificant $[F(1,29)=59.08, p<.001]$, as was Contrast 2 (easy vs. difficult) $[F(1,29)=4.41, p<.05]$. Hence, an increase in nontemporal task demands led to a progressive increase in timing variability. The main effect for trials $[F(3,87)=2.89, p<.05]$ indicated that variability remained constant across Trial $1(M=0.21 \mathrm{sec})$, Trial 2 $(M=0.21 \mathrm{sec})$, and Trial $3(M=0.21 \mathrm{sec})$, but then increased in Trial $4(M=0.22 \mathrm{sec})$. None of the interactions were significant in the analysis.

Math performance. Performance on the math verification task was evaluated with four measures: the number of problems evaluated, the percentage of problems correctly verified, sensitivity at detecting targets, and response bias in target detection.

Problems evaluated. The number of problems evaluated during each trial provides a rough index of task difficulty and may reflect interference of the concurrent timing task. These values were calculated for each subject and submitted to a $2 \times 3 \times 4$ repeated measures ANOVA, with math (easy and difficult), timing (no-timing control, 2-sec timing, and 5-sec timing), and trials (Trials $1-4)$ as the factors. The main effect for math $[F(1,29)=$ $248.81, p<.001]$ supports the idea that the two types of problems differ in difficulty, with nearly twice as many easy problems evaluated $(M=118.4)$ as difficult problems $(M=67.4)$ during each 2 -min trial. The main effect for trials $[F(3,87)=15.10, p<.001]$ indicated that the subjects became faster at the verification task as they progressed from Trial $1(M=89.3)$ to Trial $2(M=95.7)$, Trial $3(M=93.9)$, and Trial $4(M=94.7)$. However, this result is compounded by the significant timing $\times$ trials $[F(6,174)=3.40, p<.01]$ and math $\times$ timing $\times$ trials $[F(6,174)=3.04, p<.01]$ interactions. The three-way interaction was subjected to tests of simple interaction effects, which showed that the timing $\times$ trials effect was restricted to the easy math condition only $[F(6,174)=$ $3.91, p<.001]$. Simple, simple main effects tests contrasting the four trials within each timing condition of the easy math problems were then conducted. The control condition $[F(3,87)=3.39, p<.02], 2$-sec condition $[F(3,87)=5.43, p<.002]$, and $5-\sec$ condition $[F(3,87)=$ $8.60, p<.001]$ were significant. In each case, the number of problems evaluated increased from Trial 1 to Trial 4 . None of the other effects in the ANOVA was significant.

Percent correct scores. One basic measure of math performance is the percentage of problems correctly verified. Percent correct scores were calculated for each subject by averaging the probability of marking a target $[p($ hit $)]$ and the probability of not marking a distractor [ $p$ (correct rejection)]. These scores were collapsed across the four trials to make the analysis comparable to that of the $A^{\prime}$ sensitivity index (see below). Thus, the data formed a $2 \times 3$ repeated measures design, with the factors being math (easy and difficult) and timing (no-timing control, 2-sec timing, and 5-sec timing). As depicted in Figure 4, the overall level of performance was quite good. However, the ANOVA uncovered a significant main effect for timing $[F(2,58)=14.96, p<.001]$, which showed that accuracy declined from the control condition $(M=94.8 \%$ correct $)$ to the 2 -sec condition $(M=$ $91.3 \%$ correct) and 5 -sec condition $(M=91.2 \%$ correct). This effect was probed with a set of orthogonal analyses. Contrast $1[F(1,29)=26.52, p<.001]$ showed that the subjects were more accurate in the control condition than in the two timing conditions combined. That is, the addition of a timing task produced a decline in nontemporal performance. Contrast 2, comparing the 2- and 5-sec conditions, was not significant $(F<1)$. Neither of the other effects in the ANOVA achieved significance.

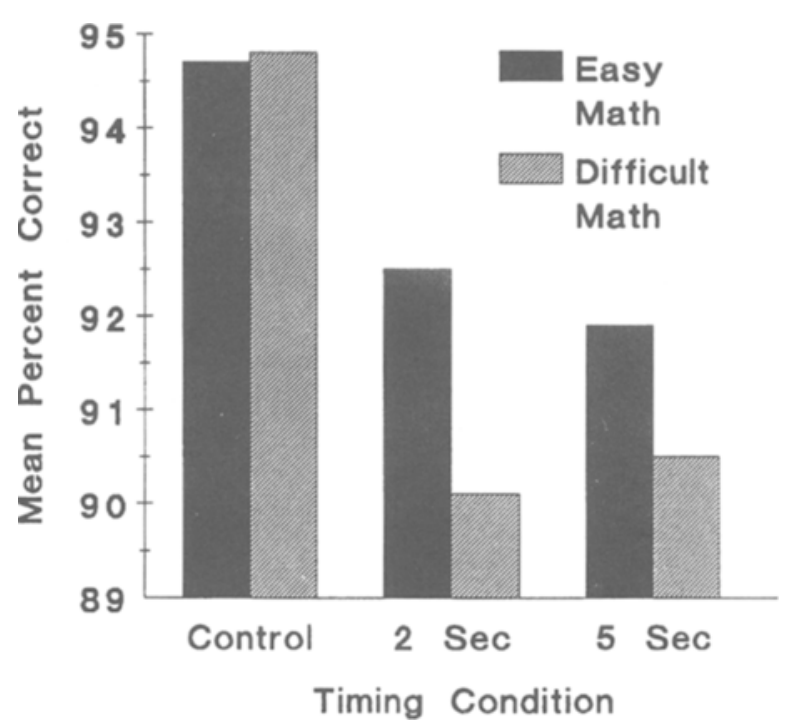

Figure 4. Mean percent correct scores in math performance for easy and difficult problems as a function of timing condition in Experiment 3. 


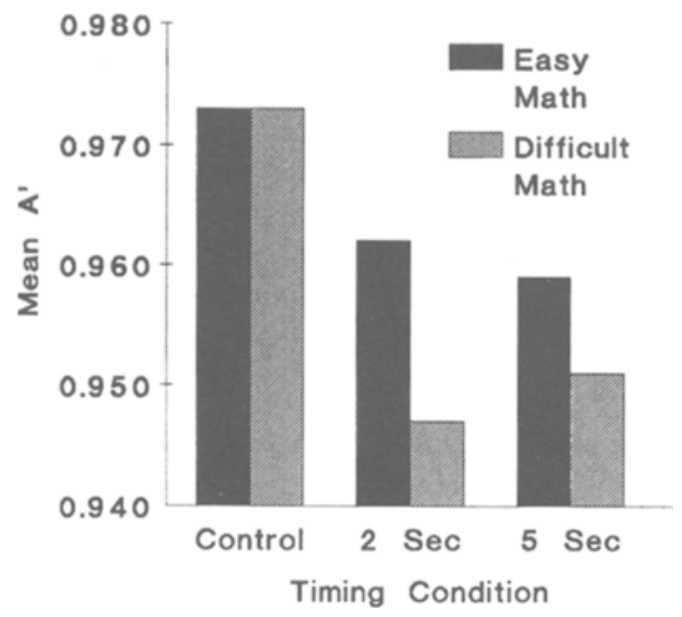

Figure 5. Mean $\boldsymbol{A}^{\prime}$ sensitivity scores in math performance for easy and difficult problems as a function of timing condition in Experiment 3.

$A^{\prime}$ sensitivity index. As in Experiment 2, the target stimuli (incorrect answers to the math problems) may be treated as random signals occurring against a noise background (the problems with correct answers), and, thus, the data can be analyzed in terms of signal detection measures of sensitivity and bias. These indices represent two independent components of the percent correct measure. The nonparametric sensitivity index $\left(A^{\prime}\right)$ was computed for each subject in each condition of a $2 \times 3$ (math $\times$ timing) repeated measures design (see Figure 5). The main effect for timing was the only significant effect in the analysis $[F(2,58)=14.76, p<.001]$. Contrast 1 $[F(1,29)=7.18, p<.01]$ showed that the subjects were more sensitive at detecting targets in the control condition $(M=.973)$ and less sensitive in the two time judgment conditions $(M=.955)$. Hence, target sensitivity was reduced under temporal/nontemporal dual-task conditions, relative to nontemporal single-task conditions. Contrast 2 (2-vs. 5-sec) was not significant.

$B^{\prime \prime}$ bias index. $B^{\prime \prime}$, the nonparametric response bias index, was calculated for each subject. The overall mean value of $B^{\prime \prime}$ was +.710 , which is very close to the corresponding value associated with visual search performance in Experiment 2. The positive value indicates that the subjects adopted a conservative criterion, tending to respond "no-no target." The scores were submitted to a math (easy and difficult) $\times$ timing (no-timing control, 2-sec timing, and 5-sec timing) repeated measures ANOVA, and both main effects were significant (see Figure 6). The effect for math $[F(1,29)=15.74, p<.001]$ showed that the two math conditions tended to evoke different responses, with the easy condition associated with larger magnitude $B^{\prime \prime}$ scores $(M=+.826)$ relative to the difficult math condition $(M=+.594)$. This finding runs counter to that of Experiment 2, where the more difficult search task was associated with a relatively larger value of $B^{\prime \prime}$. However, the primary result of interest concerns the main effect for timing $[F(2,58)=5.71, p<.01]$. This effect was analyzed with orthogonal comparisons, and Contrast $1[F(1,29)=7.18, p<.01]$ uncovered a significant difference between the control condition $(M=$ +.590 ) and the two time judgment conditions combined $(M=+.770)$. This result indicates that the timing tasks caused a shift in bias toward a more cautious approach. That is, the added demands of a concurrent timing task prompted the subjects to adopt a strategy in which they tended to pass over targets (i.e., to make more misses, in signal detection terminology). Contrast 2 , comparing the 2 - and 5-sec timing conditions, was not significant $(F<1)$. The math $\times$ timing interaction was not significant.

Summary. The results of Experiment 3 form a clear pattern. As predicted, the math verification task interfered with timing performance both by lengthening temporal productions and by rendering the productions more variable. Furthermore, all three timing measures showed that the difficult version of the task caused a greater disruption of timing than did the easy version. Timing responses on the 5-sec timing task tended to be more variable than those of the 2-sec timing task, and responses became both longer and more variable across trials. The most important aspect of Experiment 3, however, involves the analysis of nontemporal task performance. Not only did nontemporal demands disrupt timing performance but timing disrupted nontemporal performance as well. The data show a clear pattern of mutual temporal and nontemporal dual-task interference. Compared with control conditions (where the only task was math), the addition of a concurrent timing task caused a measurable decline in math performance. The subjects made more errors, they became less sensitive (i.e., less able to detect the targets), and even their decision making was altered (they became more conservative in their responses). These effects are exactly what one would expect if subjects were not giving their full attention to the task.

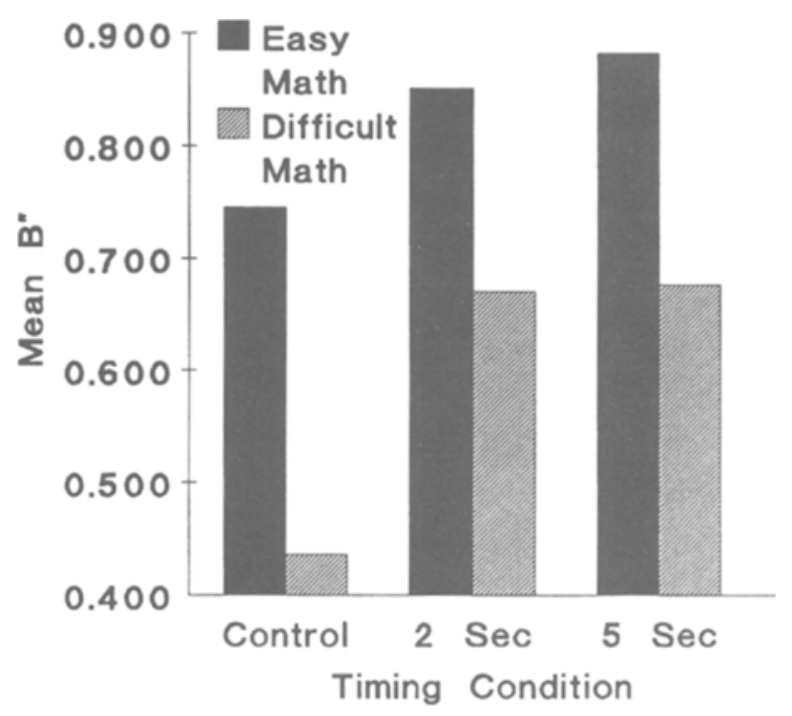

Figure 6. Mean $B^{\prime \prime}$ response bias scores in math performance for easy and difficult problems as a function of timing condition in Experiment 3. 
Table 2

Summary of Interference Effects in Timing Performance

\begin{tabular}{ccc}
\hline & Timing Versus & Easy Versus \\
Measure & Timing + Task & Difficult Task \\
\hline
\end{tabular}

Experiment 1: Pursuit Rotor Tracking

\begin{tabular}{|c|c|c|}
\hline \\
\hline Temporal production & No & No \\
\hline Standard deviation & Yes & No \\
\hline Coefficient of variation & Yes & No \\
\hline \multicolumn{3}{|c|}{ Experiment 2: Visual Search } \\
\hline Temporal production & Yes & Yes \\
\hline Standard deviation & Yes & No \\
\hline Coefficient of variation & Yes & No \\
\hline \multicolumn{3}{|c|}{ Experiment 3: Mental Arithmetic } \\
\hline Temporal production & Yes & Yes \\
\hline Standard deviation & Yes & Yes \\
\hline Coefficient of variation & Yes & Yes \\
\hline
\end{tabular}

Note-Yes $=$ the presence of an effect; No $=$ the absence of an effect.

\section{GENERAL DISCUSSION}

The research produced a mixed pattern of interference effects between temporal and nontemporal tasks. These findings provide important information concerning the role and nature of processing resources in time perception.

\section{Summary of Timing Performance}

The time judgment data, summarized in Table 2, show the classic interference effect in timing. Nontemporal task demands disrupted timing performance in each experiment. That is, temporal productions became longer and/or more variable with the addition of a concurrent nontemporal task. The magnitude of these effects was remarkably similar across the three experiments, indicating that the different nontemporal tasks exerted a similar degree of disruption in timing (cf. Figures 1,2, and 3). These results are consistent with the wide range of interference studies, reviewed earlier, that suggest that timing depends on a pool of generalized processing resources. Experiments 2 and 3 showed a significant, graded deterioration in timing performance (as measured by mean production scores) from the control to easy to difficult task conditions. Experiment 3 also showed a corresponding increase in variability (both $S D$ and coefficient of variation scores) across the three conditions. These results are in line with the predictions of the attentional allocation model. As more resources are drawn from timekeeping functions to meet nontemporal task demands, timing performance becomes more unreliable because fewer temporal cues are processed and stored.

Two other aspects of timing performance deserve comment. First, each experiment showed a linear increase in the magnitude of temporal productions from Trials 1 to 4 . This lengthening effect occurred across all treatment conditions, although the effect was stronger in the 5-sec timing conditions than in the 2-sec timing conditions. The lengthening effect represents a judgment bias that has been observed in many other studies involving serial productions (Eson \& Kafka, 1952; Falk \& Bindra, 1954; Hicks \& Allen, 1979; Ross, 1969; Shect- man, 1970; M. Treisman, 1963). The phenomenon has been attributed to a decline in "temporal arousal" (M. Treisman, 1963) or a "vigilance decrement" (Hicks \& Allen, 1979) brought about by task monotony. The increase in time judgment variability across trials observed in Experiments 1 and 3 is also consistent with this view. These results can be accommodated by any number of theoretical accounts emphasizing the role of processing resources in time perception.

The other noteworthy result in the timing data involves the variability of the 2-sec versus 5-sec temporal productions. In Experiment 1, coefficient of variation scores were larger for the 2-sec productions and smaller for the 5-sec productions. This result is similar to that reported by Grondin, Metthe, and Koren (1994), who argued that shorter productions are more variable because they require more frequent interventions of the motor system. However, one must question the robustness of this finding, given that, in Experiment 2, no effect was found and, in Experiment 3, the opposite result was obtained. The variability of temporal productions was more consistently related to nontemporal task demands than to target duration.

\section{Summary of Nontemporal Performance}

Nontemporal task performance is summarized in Table 3. One constant feature of nontemporal task performance across the three experiments involves the easy and difficult versions of each nontemporal task. The various performance measures confirmed that these manipulations were successful, with the difficult task conditions associated with slower responding, less accuracy, and/or reduced perceptual sensitivity, relative to the easy task conditions. These results correspond with the timing data, which show a decrement in time judgment performance as a function of nontemporal task demands. According to the attentional allocation model, time judg-

Table 3

Summary of Interference and Task Difficulty Effects in Nontemporal Task Performance

\begin{tabular}{ccc}
\hline & Task Versus & Easy Versus \\
Measure & Task + Timing & Difficult Task \\
\hline
\end{tabular}

Experiment 1: Pursuit Rotor Tracking

\begin{tabular}{|c|c|c|}
\hline \\
\hline Time on target & No* & Yes \\
\hline \multicolumn{3}{|c|}{ Experiment 2: Visual Search } \\
\hline Characters per second & No & Yes \\
\hline$A^{\prime}$ Sensitivity index & No & Yes \\
\hline$B^{\prime \prime}$ Bias index & No & Yes $\dagger$ \\
\hline \multicolumn{3}{|c|}{ Experiment 3: Mental Arithmetic } \\
\hline Problems evaluated & No & Yes \\
\hline Percent correct & Yes & No \\
\hline$A^{\prime}$ Sensitivity index & Yes & No \\
\hline$B^{\prime \prime}$ Bias index & Yes & Yes + \\
\hline
\end{tabular}

Note-Yes $=$ the presence of an effect; No $=$ the absence of an effect. "Less interference occurred under dual-task (tracking + timing) conditions involving the difficult (fast-target) version of the task. tThe difficult task condition produced a stricter criterion (relatively greater bias to respond "no"). ¥The difficult task condition produced a more lax criterion (relatively greater bias to respond "yes"). 
Table 4

Classification of Tasks Based on Their Reliance on Different Combinations of Specialized Resource Pools

\begin{tabular}{lll}
\hline & Perceptual/Cognitive & \multicolumn{1}{c}{ Response } \\
\hline Verbal & Print reading & Speech \\
& Voice understanding & \\
& Rehearsal & \\
& Mental arithmetic & \\
& Logical reasoning & \\
Spatial & Velocity flow fields & Manual control \\
& Spatial relations & Keyboard presses \\
& Mental rotation & \\
& Image transformations & \\
\hline
\end{tabular}

Note-From "Processing Resources and Attention" by Christopher D. Wickens (1991). In D. L. Damos (Ed.), Multiple-Task Performance (pp. 3-34, Fig. 1.4). London: Taylor \& Francis. Copyright 1991 by Taylor \& Francis. Adapted with permission.

ment performance deteriorated because fewer resources were available for temporal processing.

However, the main test of the model concerns patterns of bidirectional interference between the temporal and nontemporal tasks, as revealed by comparisons of singleversus dual-task performance. Experiments 1 and 2 showed a performance decrement from single- to dualtask conditions for timing only. There was no corresponding decline in nontemporal task performance. In fact, tracking performance in some conditions of Experiment 1 improved (a concurrence benefit) with the addition of a timing task. A clear picture of bidirectional interference occurred only in Experiment 3. In this case, mental arithmetic disrupted timing performance, and timing disrupted mental arithmetic performance. This pattern of bidirectional, mutual interference is consistent with the idea that the temporal and nontemporal tasks draw from a common pool of limited attentional resources.

As a whole, the data provide limited support for the attentional allocation model. The pattern of interference between temporal and nontemporal task performance was asymmetrical in Experiments 1 and 2 (temporal interference only) and symmetrical only in Experiment 3 (both temporal and nontemporal interference). Thus, two basic questions must be addressed: (1) Why does timing disrupt concurrent mental arithmetic but not visual search or pursuit rotor tracking? (2) Why do all three nontemporal tasks (pursuit rotor, visual search, and mental arithmetic) disrupt concurrent timing? A more sophisticated framework than the attentional allocation model is needed to account for these effects. Ideally, such a framework should be able to specify the nature of attentional resources in timing and describe the mechanisms of attentional sharing between concurrent temporal and nontemporal tasks.

\section{Resources, Timing, and Interference}

Limited attempts have been made to incorporate time perception into mainstream theoretical models of attentional resources and dual-task timesharing (see Wickens, 1992, pp. 394-395). However, two models-multiple resource theory and the working memory model-are of particular interest, as they include many issues pertinent to the present discussion. Although they differ on some details, the two models share many common features.

Multiple resource theory. The main elements of multiple resource theory have been outlined in several important publications (Kantowitz \& Knight, 1976; Navon \& Gopher, 1979, 1980; Wickens, 1980, 1984, 1986, 1991, 1992). The theory is an extension of Kahneman's (1973) capacity theory of attention, which postulates the existence of a single reservoir of limited processing resources; interference occurs when the demands of two (or more) concurrent tasks exceed available capacity. Although the capacity theory accounts for many findings, Wickens (1984) describes a number of effects that it cannot explain. Such phenomena include difficulty insensitivity, in which increases in the difficulty of one task have no effect on performance of a concurrent task, and difficulty uncoupling, in which a relatively easy task may cause more dual-task interference than a relatively difficult task. These and other effects led to the development of multiple resource theory, which argues that there are a number of separate pools of specialized processing resources. In this view, maximum interference occurs between tasks that rely primarily on the same specialized pool(s) of resources, whereas minimal (or no) interference occurs between tasks drawing from different resource pools (referred to as disjoint resources by Navon \& Gopher, 1980). Many tasks depend on some combination of different resources, and so the resource overlap between any two tasks may be only partial. Partial overlap results in an intermediate degree of dual-task interference.

Wickens $(1984,1992)$ has tentatively identified several dichotomies that define individual resource pools. These dichotomies relate to processing stages (perceptual/central resources ${ }^{4}$ vs. response-based resources), processing codes (spatial vs. verbal resources), and modalities (visual vs. auditory). In a revised formulation (Wickens, 1991), the modalities dimension was dropped, thus leaving a $2 \times 2$ resource matrix formed by combining the two stages and two codes. Wickens $(1991$, p. 18) identified particular tasks with the four combinations of resource pools (see Table 4). Tasks that share resources across one or both dimensions are more likely to interfere with one another.

The nontemporal tasks used in the present research can be mapped directly onto this framework. Pursuit rotor tracking involves primarily spatial and responsebased resources, visual search relies on spatial and perceptual/central resources, and mental arithmetic is associated with verbal and perceptual/central resources. How does prospective timing fit into this scheme? In terms of Wickens's (1991) processing stages, timing is probably aligned with perceptual/central processing. Although subjects must always execute some overt response to make their time judgments (buttonpresses at 2- and 5-sec rates in the present case), the response demands are minor in comparison with the perceptual and cognitive processes involved. In terms of processing codes, timing probably depends primarily (but not exclusively) on ver- 
bal rather than spatial resources. This assumption is based on two considerations. First, subvocal counting is a common and effective strategy for timing relatively short intervals (Poynter, 1989). Although strategies involving visual and motor processes may also be used, counting is probably the predominant strategy (see Brown, Newcomb, \& Kahrl, 1995, p. 536). Second, dualtask experiments indicate that temporal order information requires verbal rather than spatial resources (e.g., Healy, 1975; Klapp, Marshburn, \& Lester, 1983; Klapp \& Netick, 1988). Sequential order is considered to be one of the main attributes of psychological time (Fraisse, 1978, 1984; Michon \& Jackson, 1984), and, to the extent that temporal order is related to perceived duration, it is reasonable to assume that they both involve similar sets of processing resources.

Multiple resource theory provides a plausible answer to the question concerning interference in the nontemporal tasks. Timing disrupts mental arithmetic because both tasks rely on the same resource pools-namely, perceptual/central resources and verbal resources. Competition for these limited resources leads to a mutual deterioration in math and timing. Timing does not disrupt visual search or pursuit rotor tracking, because these tasks rely on different sets of resources. The theory is less successful at explaining why all three nontemporal tasks disrupt timing performance. Mental arithmetic creates interference because of a direct competition for perceptual/central and verbal resources. Although the visual search task is not affected by concurrent timing, timing is disrupted by visual search, perhaps because both tasks rely on perceptual/central resources. In fact, asymmetry in dual-task interference is not unusual (see Tsang, Shaner, \& Vidulich, 1995; Wickens, 1980, pp. 244-249). Wickens (1980) argues that dual-task interference is a joint function of the competition for specialized resources and the degree to which those resources contribute to task performance. Difficulty insensitivity for one of the tasks may result if the resource contribution is small, even though both tasks share the same resource pool. In the present case, visual search requires a large enough share of perceptual/central resources to adversely affect concurrent timing performance, whereas those resources consumed by timing may not be sufficient to degrade concurrent search performance. However, the theory cannot explain why the pursuit rotor tracking task interferes with concurrent timing performance. According to Wickens's (1991) model, the two tasks rely on disjoint resources and should not interfere (see Table 2).

Working memory model. The working memory model represents an alternative conceptualization of short-term memory. The model bears many similarities to multiple resource theory, including an emphasis on specialized limited-capacity resources. The model was first outlined by Baddeley and Hitch (1974), and the main features of the current version are summarized in several recent publications (see Baddeley, 1986, 1992a, 1992b, 1993, 1994).
The working memory system is composed of three components: a central executive that handles higher level cognitive processes and directs the activities of two secondary components (or "slave systems"), the phonological loop and the visuospatial sketchpad. The phonological (or articulatory) loop is responsible for maintaining and manipulating speech-based information. The phonological loop is divided into two functional parts (Baddeley, 1992a, 1992b; Baddeley, Lewis, \& Vallar, 1984). One part is a phonological store, a short-term (1-2 sec) buffer memory for acoustic information; the other is an articulatory control process, responsible for inner speech and subvocalization. The visuospatial sketchpad is responsible for manipulating visual images and performing visuospatial tasks (Baddeley \& Lieberman, 1980; Barton, Matthews, Farmer, \& Belyavin, 1995; Vecchi, Monticellai, \& Cornoldi, 1995). Both the phonological loop and the visuospatial sketchpad possess their own limited pool of specialized resources (see Logie, Zucco, \& Baddeley, 1990).

The central executive is a central control supervisory system responsible for reasoning, decision making, and language comprehension. Central executive functions are essentially attentional in nature (Baddeley, 1990, 1993), and they may include conscious awareness (Baddeley, 1992a). The role of the central executive in dualtask performance is twofold. First, the central executive is thought to possess general-purpose resources (Logie et al., 1990; Teasdale et al., 1995). These resources may be allocated to the phonological loop and the visuospatial sketchpad if their specialized resources are depleted by task demands. However, resources drained from the central executive will produce a corresponding disruption of any ongoing activities performed under executive control (e.g., Baddeley \& Hitch, 1974). Second, the central executive integrates information from multiple sources and coordinates dual-task performance (Baddeley, 1993; Baddeley, Logie, Bressi, Della Sala, \& Spinnler, 1986). Baddeley $(1986,1990,1992 a)$ has likened the central executive to Norman and Shallice's (1986) supervisory attentional system (SAS) - a limited-capacity controller that directs actions, schedules responses, and monitors ongoing behavior.

How does the working memory model apply to the present research? The pursuit rotor task (Experiment 1) has been linked to the visuospatial sketchpad (Baddeley, 1992a; Baddeley et al., 1975; Baddeley \& Lieberman, 1980). The visual search task (Experiment 2) would also depend on visuospatial sketchpad resources. Mental arithmetic (Experiment 3 ) has been associated primarily with the central executive (Heathcote, 1994; Hitch, 1978; Lemaire, Abdi, \& Fayol, 1996; Morris \& Jones, 1990), and there is also evidence for the involvement of the phonological loop (Logie \& Baddeley, 1987; Logie et al., 1990). Prospective timing is a conscious, intentional task, requiring continuous updating of the elapsed time. These elements logically align timing with the central executive (see also Morris \& Jones, 1990). Indeed, Bad- 
deley (1992a, 1994) has suggested that the central executive may be fractionated into several separate executive subsystems; prospective timing may be controlled by one of these subsystems. The executive timing subsystem may also rely on the phonological loop insofar as timing involves subvocal counting.

The working memory explanation of interference in nontemporal task performance is similar to that offered by the multiple resource theory. Concurrent timing disrupts mental arithmetic because both tasks are central executive (and possibly phonological loop) functions. Thus, the two tasks directly compete for the same resources, leading to mutual interference. Visual search and pursuit rotor tracking, however, rely mainly on the visuospatial sketchpad, and so competition for central timing resources is reduced. The working memory model also accounts for the question of why all three nontemporal tasks disrupt timing performance. The central executive is responsible for coordinating information and scheduling responses in dual-task situations. Thus, central executive resources must be shared between timing and the task of coordinating timing with the concurrent nontemporal task. This coordination process leaves a suboptimal level of resources available for timing, and so timing performance suffers. Moreover, increased nontemporal task demands disrupt timing to a greater degree because a difficult task uses all the resources associated with a given slave system and begins to draw upon the general resources of the central executive. The result is that even fewer resources are available for processing time.

\section{Conclusions}

A substantial interference effect in timing performance was obtained in each experiment. Although this result can be explained by the attentional allocation model, the model cannot explain the findings regarding nontemporal performance. The essential weakness of the model is that it is too simple. Multiple resource theory is able to explain more of the findings. The theory readily accounts for nontemporal performance in all three experiments. It also explains the interference effect in timing in Experiments 2 and 3. All these effects are explicable in terms of the competition (or lack of competition) for specialized resources. However, multiple resource theory fails to explain why the interference effect in timing occurred in Experiment 1, when in fact it predicts no such interference. The working memory model provides a more comprehensive account of both temporal and nontemporal task performance. The patterns of interference and lack of interference observed in nontemporal task performance are explained in terms of common and disjoint resources. The advantage of the working memory model is that it also can account for the interference effect in timing in all three experiments. According to the model, this effect occurs because the coordination of dual tasks will itself use some of the central resources ordinarily allocated to timing.

Direct comparisons of the multiple resource theory and working memory model pose a special challenge.
Both are designed to handle the same types of phenomena and so rely on similar concepts. The main difference is that the working memory model includes a provision for general-purpose resources (the central executive), whereas multiple resource theory more strictly emphasizes specialized resource pools. However, multiple resource theorists (e.g., Wickens, 1984) have suggested that there may be a pool of general, undifferentiated resources available to all tasks. Wickens $(1991$, p. 21$)$ has also speculated on the existence of an "executive mechanism" responsible for scheduling and coordinating multiple tasks. Indeed, the central executive component of working memory and the perceptual/central resource pool of multiple resource theory share many similarities. Although the working memory model offers the best explanation of the present findings, a definitive theoretical account awaits further testing. One direction for future research would be to combine timing tasks with specific procedures or effects associated with each model. For example, researchers in working memory have identified particular tasks with specific components of the working memory system. On the basis of the present results, one would expect that tasks associated with the central executive would lead to mutual interference with concurrent timing tasks, whereas tasks aligned with the phonological loop or visuospatial sketchpad would interfere with timing only. Similarly, tasks that have been linked to specific combinations of resources in multiple resource theory (see Table 4) should be tested systematically, and the patterns of interference should be examined. Nontemporal tasks that show bidirectional interference are assumed to share common resources with timing.

Certain methodological issues may be addressed in future investigations. These issues include the timing task itself, the nature of the nontemporal tasks, and the allocation of resources to concurrent temporal and nontemporal processing. First, different timing tasks may produce different patterns of interference. Although much of the discussion has centered on the nontemporal tasks, it is important also to examine the range of timing tasks that interfere with nontemporal performance. For example, timing tasks that lend themselves to a subvocal counting strategy (as in the present case) may be especially disruptive for concurrent verbal or numerical processing tasks, whereas timing tasks that preclude counting (such as judgments of very short or very long intervals) may be less disruptive. Research involving various intervals, time judgment methods, and timing strategies would help define the nature and extent of the interference effect. A second methodological issue involves nontemporal task difficulty, or workload. The mixed pattern of bidirectional interference across studies could be explained in terms of the comparative difficulty of different nontemporal tasks. That is, if one task requires fewer resources than another, then it could more easily absorb the added demands of a concurrent timing task and show no interference. The task requiring more resources would be more susceptible to interference from timing. Future researchers may seek to equate the diffi- 
culty level of nontemporal tasks via such procedures as the secondary task technique (designed to measure residual capacity not used by a concurrent or primary task), physiological indices of resource demand, or subjective ratings (see Wickens, 1992, pp. 393-402). A serious complication in workload assessment, however, is that many tasks rely on specialized resources (Gopher \& Donchin, 1986; O'Donnell \& Eggemeier, 1986; Wickens, 1992). The third issue concerns the allocation of resources to temporal and nontemporal processing. In the present experiments, the subjects were instructed to give equal priority to the temporal and nontemporal tasks. This procedure corresponds to the $50 \% / 50 \%$ condition in Macar's attentional sharing experiments on the interference effect (Grondin \& Macar, 1992; Macar et al., 1994). But despite these instructions, subjects may actually treat one task as primary and the other as secondary. One potential solution would be to test a wider range of allocation strategies, with subjects instructed to devote different proportions of attention to concurrent temporal and nontemporal tasks (e.g., Macar et al., 1994). Such data can be used to create perceiver operating characteristic (POC) functions (Grondin \& Macar, 1992) to evaluate dual-task performance (see Wickens, 1992, pp. 366373). However, it should be noted that this procedure is associated with its own methodological difficulties and problems of interpretation (Navon, 1984; Tsang, Velazquez, \& Vidulich, 1996).

The present results, in conjunction with the previous literature and the theoretical considerations outlined above, point to three general conclusions about the nature of timing.

1 . Time perception is probably handled by generalpurpose processing resources. These are the same resources used by an executive mechanism to integrate information, coordinate actions, and oversee multitask processing. Although some investigators (e.g., Fortin et al., 1993) have argued against the idea of aligning timing with general resources, the empirical evidence on the interference effect argues strongly in its favor. This is not to say that time perception involves only executive-level generalized resources. Resources specialized for verbal, visual, and motor tasks may also be utilized to the extent that one relies on corresponding timekeeping strategies. These strategies, however, are directed by a central timing process dependent on general-purpose resources.

2 . Timing is very sensitive to cognitive demands. This effect is shown in the asymmetrical patterns of interference between temporal and nontemporal tasks. Only one nontemporal task was affected by concurrent timing, whereas timing was seriously disrupted by all three concurrent nontemporal tasks. Timing is also affected by even relatively light processing loads. In each experiment, the addition of the easy version of the nontemporal task caused a substantial disruption in timing performance. Many other studies have reported similar results. This susceptibility to cognitive workload occurs because any nonautomatized task probably taps into general-level resources to some degree (see Baddeley, 1993, p. 168). Furthermore, the prospective paradigm, combined with concurrent nontemporal task demands, creates a dualtask situation that invokes the control and coordination function of general executive resources. This reliance on central resources is why time judgment performance is often used as an indicator of overall cognitive function. In fact, timing is so sensitive to changes in cognitive processing that distorted time perception is a defining feature of many altered states of consciousness (Block, 1979; Ludwig, 1966; Tart, 1975) and is considered to be a classic symptom of various psychopathological conditions (e.g., Hibbard, Migliaccio, Goldstone, \& Lhamon, 1975; Kuhs, Hermann, Kammer, \& Tolle, 1991; Lhamon \& Goldstone, 1973). Not coincidentally, these conditions are associated with major changes in general executive functioning.

3. Timing disrupts concurrent nontemporal task performance to the extent that the nontemporal task uses the same general executive resources used by timing. This point highlights the importance of assessing performance on both the temporal and the nontemporal tasks. Measuring performance on both concurrent tasks is a routine procedure for investigators studying specialized resources, whereas time researchers typically have ignored the issue. But performance on the nontemporal task may reveal important information concerning the nature of resource demands in timing. Bidirectional interference between temporal and nontemporal tasks suggests that the two tasks rely on the same processing resources or mechanisms; asymmetrical interference (in either direction) suggests that the two tasks do not draw equally from a common resource pool. Such patterns of interference may allow investigators to specify the resource demands of temporal and nontemporal tasks more precisely.

\section{REFERENCES}

ALLEN, D. A. (1980). Filling time versus affective response to the activity that fills the time: Independent effects on time judgment? Perceptual \& Motor Skills, 51, 723-727.

AMmoNs, R. B. (1951). Effect of distribution of practice on rotary pursuit "hits." Journal of Experimental Psychology, 41, 17-22.

AshCRAFT, M. H. (1992). Cognitive arithmetic: A review of data and theory. Cognition, 44, 75-106.

AXEL, R. (1924). Estimation of time. Archives of Psychology, 12, 1-72.

BACON, S. J. (1974). Arousal and the range of cue utilization. Journal of Experimental Psychology, 102, 81-87.

BADDELEY, A. D. (1986). Working memory. Oxford: Oxford University Press, Clarendon Press.

BADDELEY, A. D. (1990). Human memory: Theory and practice. Boston: Allyn \& Bacon.

BADDELEY, A. D. (1992a). Is working memory working? The fifteenth Bartlett lecture. Quarterly Journal of Experimental Psychology, 44A, 1-31.

BADDELEY, A. D. (1992b). Working memory. Science, 255, 556-559. BADDELEY, A. D. (1993). Working memory or working attention? In A. Baddeley \& L. Weiskrantz (Eds.), Attention: Selection, awareness, and control (pp. 152-170). New York: Oxford University Press. BADDELEY, A. D. (1994). Working memory: The interface between memory and cognition. In D. L. Schacter \& E. Tulving (Eds.), Memory systems 1994 (pp. 351-367). Cambridge, MA: MIT Press.

Baddeley, A. D., Grant, S., Wight, E., \& Thomson, N. (1975). Im- 
agery and visual working memory. In P. M. A. Rabbitt \& S. Dornic (Eds.), Attention and performance $V$ (pp. 205-217). Amsterdam: North-Holland.

Baddeley, A. D., \& Hitch, G. (1974). Working memory. In G. H. Bower (Ed.), The psychology of learning and motivation (Vol. 8, pp. 47-89). New York: Academic Press.

BadDeley, A. D., LeWIS, V., \& VallaR, G. (1984). Exploring the articulatory loop. Quarterly Journal of Experimental Psychology, 36A, 233-252.

Baddeley, A. D., \& Lieberman, K. (1980). Spatial working memory. In R. S. Nickerson (Ed.), Attention and performance VIII (pp. 521539). Hillsdale, NJ: Erlbaum.

Baddeley, A. D., Logie, R., Bressi, S., Della Sala, S., \& Spinnler, H. (1986). Dementia and working memory. Quarterly Journal of Experimental Psychology, 38A, 603-618.

Barton, A., Matthews, B., Farmer, E., \& Belyavin, A. (1995). Revealing the basic properties of the visuospatial sketchpad: The use of complete spatial arrays. Acta Psychologica, 89, 197-216.

Bathurst, K., \& KeE, D. W. (1994). Finger-tapping interference as produced by concurrent verbal and nonverbal tasks: An analysis of individual differences in left-handers. Brain \& Cognition, 24, 123-136.

BeLL, P. A. (1978). Effects of noise and heat stress on primary and subsidiary task performance. Human Factors, 20, 749-752.

Block, R. A. (1979). Time and consciousness. In G. Underwood \& R. Stevens (Eds.), Aspects of consciousness (Vol. 1, pp. 179-217). New York: Academic Press.

BLock, R. A. (1990). Models of psychological time. In R. A. Block (Ed.), Cognitive models of psychological time (pp. 1-35). Hillsdale, NJ: Erlbaum.

BLock, R. A. (1992). Prospective and retrospective duration judgment: The role of information processing and memory. In F. Macar, V. Pouthas, \& W. J. Friedman (Eds.), Time, action, and cognition: Towards bridging the gap (pp. 141-152). Dordrecht, The Netherlands: Kluwer.

Bortolussi, M. R., Kantowitz, B. H., \& HaRt, S. G. (1986). Measuring pilot workload in a motion base trainer. Applied Ergonomics, 17, 278-283.

Brown, S. W. (1985). Time perception and attention: The effects of prospective versus retrospective paradigms and task demands on perceived duration. Perception \& Psychophysics, 38, 115-124.

Brown, S. W., Newcomb, D. C., \& KahrL, K. G. (1995). Temporalsignal detection and individual differences in timing. Perception, 24, 525-538.

Brown, S. W., \& StubBs, D. A. (1992). Attention and interference in prospective and retrospective timing. Perception, 21, 545-557.

Brown, S. W., Stubrs, D. A., \& West, A. N. (1992). Attention, multiple timing, and psychophysical scaling of temporal judgments. In F. Macar, V. Pouthas, \& W. J. Friedman (Eds.), Time, action, and cognition: Towards bridging the gap (pp. 129-140). Dordrecht, The Netherlands: Kluwer.

Brown, S. W., \& WEST, A. N. (1990). Multiple timing and the allocation of attention. Acta Psychologica, 75, 103-121

BURNSIDE, W. (1971). Judgment of short time intervals while performing mathematical tasks. Perception \& Psychophysics, 9, 404-406.

Casali, J. G., \& Wierwille, W. W. (1983). A comparison of rating scale, secondary-task, physiological, and primary-task workload estimation techniques in a simulated flight task emphasizing communications load. Human Factors, 25, 623-641.

Casali, J. G., \& Wierwille, W. W. (1984). On the measurement of pilot perceptual workload: A comparison of assessment techniques addressing sensitivity and intrusion issues. Ergonomics, 27, 10331050.

Casin, L., Macar, F., \& Grondin, S. (1992). Time estimation and attentional sharing. In F. Macar, V. Pouthas, \& W. J. Friedman (Eds.), Time, action, and cognition: Towards bridging the gap (pp. 177180). Dordrecht, The Netherlands: Kluwer.

Cheal, M., \& Lyon, D. R. (1992). Attention in visual search: Multiple search classes. Perception \& Psychophysics, 52, 113-138.

CoHen, S. (1971). Effects of task, interval and order of presentation on time estimations. Perceptual \& Motor Skills, 33, 101-102.
Corcoran, D. W. J., \& JaCkson, A. (1977). Basic processes and strategies in visual search. In S. Dornic (Ed.), Attention and performance $V I$ (pp. 387-411). Hillsdale, NJ: Erlbaum.

Czerwinski, M., Lightfoot, N., \& Shiffrin, R. M. (1992). Automatization and training in visual search. American Journal of Psychology, 105, 271-315.

DeWolfe, R. K. S., \& Duncan, C. P. (1959). Time estimation as a function of level of behavior of successive tasks. Journal of Experimental Psychology, 58, 153-158.

DoOB, L. W. (1971). Patterning of time. New Haven, CT: Yale University Press.

DuNCAN, J., \& Humphreys, G. W. (1989). Visual search and stimulus similarity. Psychological Review, 96, 433-458.

DUNCAN, J., \& HumphreYs, G. (1992). Beyond the search surface: Visual search and attentional engagement. Journal of Experimental Psychology; Human Perception \& Performance, 18, 578-588.

Eggemeier, F. T., \& Wilson, G. F. (1991). Performance-based and subjective assessment of workload in multi-task environments. In D. L. Damos (Ed.), Multiple-task performance (pp. 217-278). London: Taylor \& Francis.

ERIKSEN, C. W., \& YEH, Y. (1985). Allocation of attention in the visual field. Journal of Experimental Psychology: Human Perception \& Performance, 11, 583-597.

Eson, M. E., \& KAFKA, J. S. (1952). Diagnostic implications of a study in time perception. Journal of General Psychology, 46, 169-183.

EssMAN, W. B. (1958). Temporal discrimination in problem solving. Perceptual \& Motor Skills, 8, 314.

FALK, J. L., \& BindRA, D. (1954). Judgment of time as a function of serial position and stress. Journal of Experimental Psychology, 47, 279-282.

Fisher, D. L., Duffy, S. A., Young, C., \& Pollatsek, A. (1988). Understanding the central processing limit in consistent-mapping visual search tasks. Journal of Experimental Psychology: Human Perception \& Performance, 14, 253-266.

ForTIN, C., \& Breton, R. (1995). Temporal interval production and processing in working memory. Perception \& Psychophysics, 57, 203-215.

ForTin, C., \& Rousseau, R. (1987). Time estimation as an index of processing demand in memory search. Perception \& Psychophysics, 42, 377-382.

Fortin, C., Rousseau, R., Bourque, P., \& Kirouac, E. (1993). Time estimation and concurrent nontemporal processing: Specific interference from short-term-memory demands. Perception \& Psychophysics, 53, 536-548.

Fraisse, P. (1978). Time and rhythm perception. In E. C. Carterette \& M. P. Friedman (Eds.), Handbook of perception: Vol. VIII. Perceptual coding (pp. 203-254). New York: Academic Press.

FraISSE, P. (1984). Perception and estimation of time. Annual Review of Psychology, 35, 1-36.

FRITH, C. D. (1971). Strategies in rotary pursuit tracking. British Journal of Psychology, 62, 187-197.

GoLDSTONE, S. (1975). The variability of temporal judgment in psychopathology. In M. L. Kietzman, S. Sutton, \& J. Zubin (Eds.), Experimental approaches to psychopathology (pp. 393-419). New York: Academic Press.

GOPHER, D. (1986). In defence of resources: On structures, energies, pools and the allocation of attention. In G. R. J. Hockey, A. W. K. Gaillard, \& M. G. H. Coles (Eds.), Energetics and human information processing (pp. 353-371). Dordrecht, The Netherlands: Martinus Nijhoff.

GOPHER, D., \& DONCHIN, E. (1986). Workload-An examination of the concept. In K. R. Boff, L. Kaufman, \& J. P. Thomas (Eds.), Handbook of perception and human performance: Vol. II. Cognitive processes and performance (pp. 41.1-41.49). New York: Wiley

GoRDON, I. E. (1968). Interactions between items in visual search. Journal of Experimental Psychology, 76, 348-355.

GRIER, J. B. (1971). Nonparametric indexes for sensitivity and bias: Computing formulas. Psychological Bulletin, 75, 424-429.

Grondin, S., \& MACAR, F. (1992). Dividing attention between temporal and nontemporal tasks: A performance operating characteristic- 
POC-analysis. In F. Macar, V. Pouthas, \& W. J. Friedman (Eds.), Time, action, and cognition: Towards bridging the gap (pp. 119128). Dordrecht, The Netherlands: Kluwer.

Grondin, S., MetThe, L., \& Koren, S. (1994). Motor disruption in the production of time intervals with finger taps. Canadian Journal of Experimental Psychology, 48, 460-466.

GuAY, M., \& SALMONI, A. W. (1988). Effect of interpolated temporal activity on temporal short-term memory. Perceptual \& Motor Skills, 67, 743-748.

GULLIKSEN, H. (1927). The influence of occupation upon the perception of time. Journal of Experimental Psychology, 10, 52-59.

HARTON, J. J. (1938a). The influence of the difficulty of activity on the estimation of time. Journal of Experimental Psychology, 23, 270287.

Harton, J. J. (1938b). The influence of the difficulty of activity on the estimation of time: II. Journal of Experimental Psychology, 23, 428-433.

HARTON, J. J. (1942). Time estimation in relation to goal organization and difficulty of tasks. Journal of General Psychology, 27, 63-69.

HaWkes, G. R. (1972). Time perception research: An empirical basis for the study of attention. Psychonomic Monograph Supplements, 4 (12, Whole No. 60), 221-224.

Hawkes, G. R., \& Sherman, S. J. (1972). Vigilance effects for duration judgments with two levels of task demand. Perceptual \& Motor Skills, 34, 351-356.

HAWkINS, N. E., \& MEYER, M. E. (1965). Time perception of short intervals during finished, unfinished and empty task situations. Psychonomic Science, 3, 473.

HeALY, A. F. (1975). Temporal-spatial patterns in short-term memory. Journal of Verbal Learning \& Verbal Behavior, 14, 481-495.

Healy, A. F., Fendrich, D. W., \& Proctor, J. D. (1990). Acquisition and retention of a letter-detection skill. Journal of Experimental Psychology: Learning, Memory, \& Cognition, 16, 270-281.

HeathCote, D. (1994). The role of visuo-spatial working memory in the mental addition of multi-digit addends. Cahiers de Psychologie Cognitive/Current Psychology of Cognition, 13, 207-245.

Hibbard, T. R., Migliaccio, J. N., Goldstone, S., \& Lhamon, W. T. (1975). Temporal information processing by young and senior adults and patients with senile dementia. Journal of Gerontology, 30, 326-330.

Hicks, R. E., \& ALLEN, D. A. (1979). The repetition effect in judgments of temporal duration across minutes, days, and months. American Journal of Psychology, 92, 323-333.

Hicks, R.E., \& BRUNDIGE, R. M. (1974). Judgments of temporal duration while processing verbal and physiognomic stimuli. Acta Psychologica, 38, 447-453.

Hicks, R. E., Miller, G. W., Gaes, G., \& Bierman, K. (1977). Concurrent processing demands and the experience of time-in-passing. American Journal of Psychology, 90, 431-446.

Hicks, R. E., Miller, G. W., \& KINSBourne, M. (1976). Prospective and retrospective judgments of time as a function of amount of information processed. American Journal of Psychology, 89, 719-730.

Hiscock, M., Cheesman, J., Inch, R., Chipuer, H. M., \& GrafF, L. A. (1989). Rate and variability of finger tapping as measures of lateralized concurrent task effects. Brain \& Cognition, 10, 87-104.

HiTCH, G. J. (1978). The role of short-term working memory in mental arithmetic. Cognitive Psychology, 10, 302-323.

JensEn, B. E. (1975). Pretask speed training and movement complexity as factors in rotary pursuit skill acquisition. Research Quarterly, 46, 1-11.

JoU, J., \& Harris, R. J. (1992). The effect of divided attention on speech production. Bulletin of the Psychonomic Society, 30, 301-304.

Kahneman, D. (1973). Attention and effort. Englewood Cliffs, NJ: Prentice-Hall.

Kantowitz, B. H., \& KNIGHT, J. L. (1974). Testing tapping timesharing. Journal of Experimental Psychology, 103, 331-336.

KantowiTZ, B. H., \& KNIGHT, J. L. (1976). Testing tapping timesharing: II. Auditory secondary task. Acta Psychologica, 40, 343-362.

KeE, D. W., Morris, K., Bathurst, K., \& Hellige, J. B. (1986). Lateralized interference in finger tapping: Comparisons of rate and variability measures under speed and consistency tapping instructions. Brain \& Cognition, 5, 268-279.
KELLOGG, R. T. (1985). Long-term memory of unattended information. Psychological Record, 35, 239-249.

KEPPEL, G. (1982). Design and analysis: A researcher's handbook (2nd ed.). Englewood Cliffs, NJ: Prentice-Hall.

KinsBourne, M., \& Hiscock, M. (1983). Asymmetries of dual-task performance. In J. B. Hellige (Ed.), Cerebral hemisphere asymmetry: Method, theory, and application (pp. 255-334). New York: Praeger.

KLAPP, S. T. (1979). Doing two things at once: The role of temporal compatibility. Memory \& Cognition, 7, 375-381.

KLAPP, S. T. (1981). Temporal compatibility in dual motor tasks II: Simultaneous articulation and hand movements. Memory \& Cognition, 9, 398-401.

Klapp, S. T., Marshburn, E. A., \& Lester, P. T. (1983). Short-term memory does not involve the "working memory" of information processing: The demise of a common assumption. Journal of Experimental Psychology: General, 112, 240-261.

KLAPP, S. T., \& NETICK, A. (1988). Multiple resources for processing and storage in short-term working memory. Human Factors, 30, 617-632.

Klapp, S. T., Porter-Graham, K. A., \& Hoifjeld, A. R. (1991). The relation of perception and motor action: Ideomotor compatibility and interference in divided attention. Journal of Motor Behavior, 23, 155-162.

Kuhs, H., Hermann, W., Kammer, K., \& Tolle, R. (1991). Time estimation and the experience of time in endogenous depression (melancholia): An experimental investigation. Psychopathology, 24, 7-11.

LAJOY, R. J., \& SEETHOFF, P. M. (1974). Effects of familiarity, verbal response, and practice on a visual search task. Perceptual $\&$ Motor Skills, 38, 1311-1314.

Lemaire, P., ABDI, H., \& FAYOL, M. (1996). The role of working memory resources in simple cognitive arithmetic. European Journal of Cognitive Psychology, 8, 73-103.

LhAMON, W. T., \& GolDSTONE, S. (1973). Temporal information processing in schizophrenia. Archives of General Psychiatry, 28, 44-51.

LOGAN, G. D. (1978). Attention demands of visual search. Memory \& Cognition, 6, 446-453.

LOGIE, R. H., \& BADDELEY, A. D. (1987). Cognitive processes in counting. Journal of Experimental Psychology: Learning, Memory, \& Cognition, 13, 310-326.

LogIE, R. H., Zucco, G. M., \& BADDELEY, A. D. (1990). Interference with visual short-term memory. Acta Psychologica, 75, 55-74.

LuDwig, A. M. (1966). Altered states of consciousness. Archives of General Psychiatry, 15, 225-234.

MACAR, F., GrondiN, S., \& CASINI, L. (1994), Controlled attention sharing influences time estimation. Memory \& Cognition, 22, 673-686.

MADDEN, D. J., \& ALLEN, P. A. (1989). Amount and duration of attentional demands during visual search. Perception \& Psychophysics, 45, 577-585.

Marmaras, N., Vassilakis, P., \& Dounias, G. (1995). Factors affecting accuracy of producing time intervals. Perceptual \& Motor Skills, 80, 1043-1056.

Martin, G. A., Shumate, M., \& Frauenfelder, K. (1981). Experience of duration as a function of number of responses, task difficulty, and sex. Perceptual \& Motor Skills, 53, 139-145.

MARTinez, M. B. B. (1992). Testing models of time estimation. In F. Macar, V. Pouthas, \& W. J. Friedman (Eds.), Time, action, and cognition: Towards bridging the gap (pp. 173-176). Dordrecht, The Netherlands: Kluwer.

Martinez, [M.] B. B. (1994). The role of cognitive changes in immediate and remote prospective time estimations. Acta Psychologica, 85, 99-121.

Mastroianni, G. R., \& Schopper, A. W. (1986). Degradation of force-loaded pursuit tracking performance in a dual-task paradigm. Ergonomics, 29, 639-647.

MCClain, L. (1983). Interval estimation: Effect of processing demands on prospective and retrospective reports. Perception \& Psychophysics, 34, 185-189.

MCLEOD, P. (1977). A dual-task response modality effect: Support for multiprocessor models of attention. Quarterly Journal of Experimental Psychology, 29, 651-667.

MichoN, J. A. (1965). Studies on subjective duration: II. Subjective 
time measurement during tasks with different information content. Acta Psychologica, 24, 205-212.

MichON, J. A. (1966). Tapping regularity as a measure of perceptual motor load. Ergonomics, 9, 401-412.

Michon, J. A. (1972). Processing of temporal information and the cognitive theory of time experience. In J. T. Frasier, F. C. Haber, \& G. W. Muller (Eds.), The study of time (pp. 242-258). New York: Springer-Verlag.

Michon, J. A. (1985). The compleat time experiencer. In J. A. Michon \& J. L. Jackson (Eds.), Time, mind, and behavior (pp. 20-52). New York: Springer-Verlag

MiCHON, J. A., \& JACKSON, J. L. (1984). Attentional effort and cognitive strategies in the processing of temporal information. In J. Gibbon \& L. Allan (Eds.), Timing and time perception (Annals of the New York Academy of Sciences, Vol. 423, pp. 298-321). New York: New York Academy of Sciences.

Miller, G. W., Hicks, R. E., \& Willette, M. (1978). Effects of concurrent verbal rehearsal and temporal set upon judgments of temporal duration. Acta Psychologica, 42, 173-179.

MORRIS, N., \& JoNES, D. M. (1990). Memory updating in working memory: The role of the central executive. British Journal of Psychology, 81, 111-121.

NaGASAKI, H. (1990). Rhythm in periodic tapping is centrally produced. Perceptual \& Motor Skills, 71, 985-986.

Navon, D. (1984). Resources-A theoretical soup stone? Psychological Review, 91, 216-234.

Navon, D., \& Gopher, D. (1979). On the economy of the humanprocessing system. Psychological Review, 86, 214-253.

NAVON, D., \& GOPHER, D. (1980). Task difficulty, resources, and dualtask performance. In R. S. Nickerson (Ed.), Attention and performance VIII (pp. 297-315). Hillsdale, NJ: Erlbaum.

NeISSER, U. (1963). Decision time without reaction time: Experiments in visual scanning. American Journal of Psychology, 76, 376-385.

Norman, D. A., \& Shallice, T. (1986). Attention to action: Willed and automatic control of behavior. In R. J. Davidson, G. E. Schwartz, \& D. Shapiro (Eds.), Consciousness and self-regulation: Advances in research and theory (Vol. 4, pp. 1-18). New York: Plenum.

O'DONNELl, R. D., \& EGGEMEIER, F. T. (1986). Workload assessment methodology. In K. R. Boff, L. Kaufman, \& J. P. Thomas (Eds.), Handbook of perception and human performance: Vol. II. Cognitive processes and performance (pp. 42.1-42.49). New York: Wiley.

Palmer, J., AMEs, C. T., \& Lindsey, D. T. (1993). Measuring the effect of attention on simple visual search. Journal of Experimental Psychology: Human Perception \& Performance, 19, 108-130.

PASHLER, H. (1987). Target-distractor discriminability in visual search. Perception \& Psychophysics, 41, 285-292.

POYNTER, D. (1989). Judging the duration of time intervals: A process of remembering segments of experience. In I. Levin \& D. Zakay (Eds.), Time and human cognition: A life-span perspective (pp. 305321). Amsterdam: Elsevier.

RabBITt, P., CumminG, G, \& Vyas, S. (1979). Improvement, learning and retention of skill at visual search. Quarterly Journal of Experimental Psychology, 31, 441-459.

RedDing, G. M., \& Wallace, B. (1985). Cognitive interference in prism adaptation. Perception \& Psychophysics, 37, 225-230.

REISBERG, D. (1983). General mental resources and perceptual judgments. Journal of Experimental Psychology: Human Perception \& Performance, 9, 966-979.

ReISBerG, D., \& O'Shaughnessy, M. (1984). Diverting subjects' concentration slows figural reversals. Perception, 13, 461-468.

Ross, D. A. (1969). Lengthening of time estimates in four different patterns of visual light stimulation. Psychonomic Science, 16, 194-195.

Sawyer, T. F., Meyers, P. J., \& Huser, S. J. (1994). Contrasting task demands alter the perceived duration of brief time intervals. Perception \& Psychophysics, 56, 649-657.

SCHNEIDER, W., \& FISK, A. D. (1982a). Concurrent automatic and controlled visual search: Can processing occur without resource cost? Journal of Experimental Psychology: Learning, Memory, \& Cognition, 8, 261-278.

SCHNEIDER, W., \& FiSK, A. D. (1982b). Degree of consistent training:
Improvements in search performance and automatic process development. Perception \& Psychophysics, 31, 160-168.

SheCtMan, F. A. (1970). Time estimation, sequence effects and filling activities. Perceptual \& Motor Skills, 30, 23-26.

SIEGEL, B. (1990). A multivariate study of pursuit rotor skill development. Research Quarterly for Exercise \& Sport, 61, 201-205.

SмiтH, N. C. (1969). The effect on time estimation of increasing the complexity of a cognitive task. Journal of General Psychology, 81, 231-235.

SPIEGEL, M. R. (1961). Schaum's outline of theory and problems of statistics. New York: Schaum.

StefuraK, D. L., \& Boynton, R. M. (1986). Independence of memory for categorically different colors and shapes. Perception \& Psychophysics, 39, 164-174.

TART, C. T. (1975). States of consciousness. New York: Dutton.

Teasdale, J. D., Drutschel, B. H., Taylor, M. J., Proctor, L., Lloyd, C. A., Nimmo-Smith, I., \& Baddeley, A. D. (1995). Stimulusindependent thought depends on central executive resources. Memory \& Cognition, 23, 551-559.

Thomas, E. A. C., \& Brown, I., JR. (1974). Time perception and the filled-duration illusion. Perception \& Psychophysics, 16, 449-458.

ThOMas, E. A. C., \& CANTOR, N. E. (1975). On the duality of simultaneous time and size perception. Perception \& Psychophysics, 18 44-48.

Thomas, E. A. C., \& Cantor, N. E. (1978). Interdependence between the processing of temporal and non-temporal information. In J. Requin (Ed.), Attention and performance VII (pp. 43-62). Hillsdale, $\mathrm{NJ}$ : Erlbaum.

Thomas, E. A. C., \& WeAVER, W. B. (1975). Cognitive processing and time perception. Perception \& Psychophysics, 17, 363-367.

Treisman, A., VIEIRA, A., \& HAYES, A. (1992). Automaticity and preattentive processing. American Journal of Psychology, 105, 341-362.

Treisman, M. (1963). Temporal discrimination and the indifference interval: Implications for a model of the "internal clock." Psychological Monographs: General \& Applied, 77(13, Whole No. 576).

Tsang, P. S., Shaner, T. L., \& Vidulich, M. A. (1995). Resource scarcity and outcome conflict in time-sharing performance. Perception \& Psychophysics, 57, 365-378.

Tsang, P. S., Velazquez, V. L., \& Vidulich, M. A. (1996). Viability of resource theories in explaining time-sharing performance. Acta Psychologica, 91, 175-206.

Tsao, Y., Wittlieb, E., Miller, B., \& Wang, T. (1983). Time estimation of a secondary event. Perceptual \& Motor Skills, 57, 1051-1055. van der Heijden, A. H. C., Malhas, M. S. M., \& van den RoovaArt, B. P. (1984). An empirical interletter confusion matrix for continuous-line capitals. Perception \& Psychophysics, 35, 85-88.

VeCCHI, T., Monticellai, M. L., \& CoRNOLDI, C. (1995). Visuo-spatial working memory: Structures and variables affecting a capacity measure. Neuropsychologia, 33, 1549-1564.

WANNER, E., \& SHINER, S. (1976). Measuring transient memory load. Journal of Verbal Learning \& Verbal Behavior, 15, 159-167.

WARREN, M. W. (1977). The effects of recall-concurrent visual-motor distraction on picture and word recall. Memory \& Cognition, $\mathbf{5}$ 362-370.

Watkins, M. J., Watkins, O. C., Craik, F. I. M., \& Mazuryk, G. (1973). Effect of nonverbal distraction on short-term storage. Journal of Experimental Psychology, 101, 296-300.

Whitehurst, M., \& Del Rey, P. (1983). Effects of contextual interference, task difficulty, and levels of processing on pursuit tracking. Perceptual \& Motor Skills, 57, 619-628.

WiCKENS, C. D. (1980). The structure of attentional resources. In R. S Nickerson (Ed.), Attention and performance VIII (pp. 239-257) Hillsdale, NJ: Erlbaum.

Wickens, C. D. (1984). Processing resources in attention. In R. Parasuraman \& D. R. Davies (Eds.), Varieties of attention (pp. 63-102). New York: Academic Press.

WICKENS, C. D. (1986). Gain and energetics in information processing. In G. R. J. Hockey, A. W. K. Gaillard, \& M. G. H. Coles (Eds.), Energetics and human information processing (pp. 373-389). Dordrecht, The Netherlands: Martinus Nijhoff. 
Wickens, C. D. (1991). Processing resources and attention. In D. L. Damos (Ed.), Multiple-task performance (pp. 3-34). London: Taylor \& Francis.

WiCKENS, C. D. (1992). Engineering psychology and human performance (2nd ed.). New York: HarperCollins.

Wickens, C. D., \& Kessel, C. (1980). Processing resource demands of failure detection in dynamic systems. Journal of Experimental Psychology: Human Perception \& Performance, 6, 564-577.

Wierwille, W. W., \& CoNNOR, S. A. (1983). Evaluation of 20 workload measures using a psychomotor task in a moving-base aircraft simulator. Human Factors, 25, 1-16.

Wierwille, W. W., RaHimi, M., \& CASAli, J. G. (1985). Evaluation of 16 measures of mental workload using a simulated flight task emphasizing mediational activity. Human Factors, 27, 489-502.

Wilsoncroft, W. E., \& STONE, J. D. (1975). Information processing and estimation of short time intervals. Perceptual \& Motor Skills, 41, 192-194.

Wilsoncroft, W. E., Stone, J. D., \& Bagrash, F. M. (1978). Temporal estimates as a function of difficulty of mental arithmetic. Perceptual \& Motor Skills, 46, 1311-1317.

WoLFE, J. M. (1994). Guided Search 2.0: A revised model of visual search. Psychonomic Bulletin \& Review, 1, 202-238.

ZAKAY, D. (1989). Subjective time and attentional resource allocation: An integrated model of time estimation. In I. Levin \& D, Zakay (Eds.), Time and human cognition: A life-span perspective (pp. 365397). Amsterdam: Elsevier.

ZAKAY, D, (1992). On prospective time estimation, temporal relevance and temporal uncertainty. In F. Macar, V. Pouthas, \& W. J. Friedman (Eds.), Time, action, and cognition: Towards bridging the gap (pp. 109-117). Dordrecht, The Netherlands: Kluwer.

ZAKAY, D. (1993a). Relative and absolute duration judgments under prospective and retrospective paradigms. Perception \& Psychophysics, 54, 656-664.

ZAKAY, D. (1993b). The roles of nontemporal information processing load and temporal expectations in children's prospective time estimation. Acta Psychologica, 84, 271-280.
ZAKAY, D. (1993c). Time estimation methods--Do they influence prospective duration estimates? Perception, 22, 91-101.

ZAKAY, D., \& FAllaCH, E. (1984). Immediate and remote time estimation-A comparison. Acta Psychologica, 57, 69-81.

ZaKaY, D., NitZaN, D., \& GlicksoHN, J. (1983). The influence of task difficulty and external tempo on subjective time estimation. Perception \& Psychophysics, 34, 451-456.

ZBRoDOFF, N. J., \& LoGAN, G. D. (1986). On the autonomy of mental processes: A case study of arithmetic. Journal of Experimental Psychology: General, 115, 118-130.

\section{NOTES}

1. The formula for $A^{\prime}$ may be written as

$$
A^{\prime}=.5+\frac{[p(\text { hit })-p(\mathrm{fa})][1+p(\mathrm{hit})-p(\mathrm{fa})]}{[4 p \text { (hit) })][1-p(\mathrm{fa})]},
$$

where $p$ (hit) is the probability of a hit and $p(\mathrm{fa})$ is the probability of a false alarm.

2. The formula for $B^{\prime \prime}$ may be written as

$$
B^{\prime \prime}=\frac{\{p(\text { hit })[1-p(\text { hit })]\}-\{p(\mathrm{fa})[1-p(\mathrm{fa})]\}}{\{p(\text { hit })[1-p \text { (hit })]\}+\{p(\mathrm{fa})[1-p(\mathrm{fa})]\}},
$$

where $p($ hit $)$ is the probability of a hit and $p(\mathrm{fa})$ is the probability of a false alarm.

3. Two subjects were not included in this analysis because a lack of false alarms in some conditions precluded the calculation of $B^{\prime \prime}$. The analysis reported here is based on the remaining 31 subjects.

4. In some writings (e.g., Wickens, 1991), these resources are referred to as perceptual/cognitive resources.

(Manuscript received March 18, 1996; revision accepted for publication November 6,1996 .) 